\title{
The significance of climate variability on early modern European grain prices
}

\author{
Fredrik Charpentier Ljungqvist ${ }^{1,2,3}$ (D) Peter Thejll ${ }^{4}$ Bo Christiansen ${ }^{4}$. \\ Andrea Seim $^{5,6} \cdot$ Claudia Hartl $^{7}$. Jan Esper ${ }^{7}$
}

Received: 25 August 2020 / Accepted: 29 January 2021 / Published online: 9 March 2021

(c) The Author(s) 2021

\begin{abstract}
Grain was the most important food source in early modern Europe (c. 1500-1800), and its price influenced the entire economy. The extent to which climate variability determined grain price variations remains contested, and claims of solar cycle influences on prices are disputed. We thoroughly reassess these questions, within a framework of comprehensive statistical analysis, by employing an unprecedentedly large grain price data set together with state-of-the-art palaeoclimate reconstructions and long meteorological series. A highly significant negative grain price-temperature relationship (i.e. colder $=$ high prices and vice versa) is found across Europe. This association increases at larger spatial and temporal scales and reaches a correlation of -0.41 considering the European grain price average and previous year June-August temperatures at annual resolution, and of -0.63 at decadal timescales. This strong relationship is of episodic rather than periodic (cyclic) nature. Only weak and spatially inconsistent signals of hydroclimate (precipitation and drought), and no meaningful association with solar variations, are detected in the grain prices. The significant and persistent temperature effects on grain prices imply that this now rapidly changing climate element has been a more important factor in European economic history, even in southern Europe, than commonly acknowledged.
\end{abstract}

Keywords Grain prices · Harvest yields · Temperature variability · Drought variability $\cdot$ Solar variability $\cdot$ Early modern period $\cdot$ Europe

JEL Classification $\mathrm{N} 53 \cdot \mathrm{N} 13 \cdot \mathrm{O} 11 \cdot \mathrm{C} 00 \cdot \mathrm{Q} 21 \cdot \mathrm{Q} 50$

Fredrik Charpentier Ljungqvist

fredrik.c.1@historia.su.se

Extended author information available on the last page of the article 


\section{Introduction}

The importance of grain in early modern (c. 1500-1800) Europe can hardly be overstated as grain-based food, in most regions, represented $70-80 \%$ of the caloric intake for a majority of the population. Such a large proportion of workers' income was spent on grain-based food that grain prices, to a large extent, determined the real wage levels and affected general consumer patterns (e.g. Hoskins 1964, 1968; Appleby 1979; Van Zanden 1999; Allen 2000; Campbell 2010). The entire economy was highly grain dependent, with taxes and land rents largely obtained from the surplus of grain agriculture (Le Roy Ladurie and Goy 1982; Leijonhufvud 2001; Edvinsson 2009). This predominant role of cereals in the economy made grain trade one of the most important and well-monitored fields of commerce (Rahlf 1996; Persson 1999; Federico 2011; Bateman 2011; Chilosi et al. 2013). An inadequate supply of grain, triggering high prices, frequently caused economic destitution, civil unrest, malnutrition, and even famines (e.g. Abel 1974; Pfister 1988; Mauelshagen 2010; Alfani and Ó Gráda 2017).

The causes of variations in grain yields and prices in early modern (c. 1500-1800) Europe are a research topic first initiated over two centuries ago (e.g. Herschel 1801). Determining the extent to which grain prices were affected by climate variability $^{1}$, or mediated through climate-influencing factors such as solar variability, and whether such relationships were episodic or periodic (cyclic) ${ }^{2}$, are long-standing research problems approached from both (economic) history and the environmental sciences. This research has employed data of various quantities and qualities and has been conducted at different levels of statistical rigour. Here, we revisit the question of direct influences of climate variability, and indirect influences of solar variability, on grain prices in early modern Europe within a framework of comprehensive and internally consistent statistical analysis. ${ }^{3}$ To achieve these goals, we employ the so far largest collection of grain price series of multi-centennial length from across Europe, early instrumental climate series, state-of-the-art palaeoclimate reconstructions, and the latest generation of solar variability estimates. We first provide an overview of previous work on the influence of climate (Sect. 2.1) and solar variability (Sect. 2.2) on grain prices in early modern Europe, then identify research

\footnotetext{
1 Throughout this article, climate denotes the average weather conditions over a longer time period and includes both the mean and the variability of this long-term average; climatic change refers to changes in the mean of the climate as well as changes in frequency and magnitude of certain extreme conditions like very cold summers.

2 Periodic and episodic mean occurring at regular and irregular, respectively, intervals. There is some overlap in the definitions, but in general a periodic time-series will have a well-defined peak in its power spectrum while episodic series will not.

3 As discussed in Sect. 3.3 and "Appendix 1", we include the Sun in our analysis, in terms of a potential solar influence on climate, and subsequently via climate on growth conditions for grain prices, but not as a representative of a direct influence on plant growth. Although the solar cycle is linked to variations in the intensity of sunlight the variation is so small (about $0.1-0.2 \%$ in visible light) that it most likely has a relatively small effect on growth conditions. The possibility that solar activity influences the climatee.g. the hydrological cycle via clouds-is among the more likely possibilities that makes the analysis of solar activity, as a potential climate-modulating factor, interesting.
} 
gaps (Sect. 2.3), present the data and methods (Sect. 3), and results of our analyses (Sect. 4), and finally discuss various implications and associated uncertainties (Sect. 5).

\section{State of the art}

\subsection{Climate variability and grain prices in early modern Europe}

The influence of long-term climate variability on early modern grain yields and prices, and more generally on the economy, has for a long time been a matter of contrasting views. Positions in historical scholarship have ranged from climate determinism to, more commonly, an outright rejection of detectable climate influences (for a review, see Ljungqvist et al. 2021). A pioneering study by Brückner (1895), covering the eighteenth and nineteenth centuries, concluded that higher rainfall decreased grain yields and increased grain prices in western and central Europe, whereas the opposite was observed in eastern Europe, promoting climate-influenced grain trade patterns and policies. Beveridge $(1921,1922)$ studied the co-variance in periodicity between wheat prices and precipitation in western and central Europe within a more advanced statistical framework. He reported, like Brückner (1895), higher wheat prices during periods with more rainfall.

These early works stand in contrast to later prevailing views. Many historians have, until recently, not considered climate variability as an explanatory factor for variations in harvests or grain prices over longer timescales (see, e.g. Mauelshagen 2010). In his influential work on early modern food crises, Abel (1974) understood adverse climate impacts as randomly occurring shocks. De Vries (1980) acknowledged significant climate influences on grain harvests and prices, but still argued that climatic crises had little to no long-term importance in economic history. Persson (1999), in his monumental work on the early modern grain market, appears not to have envisioned climate change as a factor behind long-term grain price trends, and Fogel (1992) even went as far as to attempt to disprove the connection between adverse climate conditions for agriculture and the occurrence of famines in early modern Europe. These presumptions are, as discussed in Chakrabarty (2009) and Campbell (2010), rooted in theoretical foundations of historical scholarship to search exclusively for endogenous explanations, internal to human society, and a reluctance to give exogenous (environmental) factors a role of agency in history.

Despite the scepticism expressed by many historians, modern research has detected a robust influence of climate-induced harvest variations on both grain prices and real wage levels across early modern Europe. ${ }^{4}$ Dry summers were

\footnotetext{
${ }^{4}$ See, for example, Pfister (1988, 2005) for Switzerland, Pfister and Brázdil (1999) for Central Europe more generally, Brázdil and Durd'áková (2000) for the Czech Republic, Bauernfeind and Woitek (1999) for Germany, Edvinsson et al. (2009) for Sweden, Huhtamaa (2018) for Finland, and Esper et al. (2017) for entire Europe. Some studies have also addressed the medieval period with somewhat mixed results. Söderberg (2006) found no temperature-grain price relationship (likely because he used a Northern Hemisphere temperature reconstruction rather than temperature data relevant for Europe), while Campbell (2010, 2016), Pribyl (2017), and Bekar (2019) for England, and Camenisch (2015) for the Burgundian Low Countries, found significant local to regional climate-grain price relationships.
} 
advantageous, and cold springs and wet summers detrimental, for wheat in England (Scott et al. 1998; Brunt 2015), most of France (Le Roy Ladurie 1967), and across central Europe (Pfister 2005), although drought also posed a significant risk in the latter region (Brázdil et al. 2019). Short and cold growing seasons threatened grain yields in northern Europe (Huhtamaa 2018). Spring droughts and cold winters were important hazards in Mediterranean Europe (White et al. 2018).

The existence of distinctive climate variability on harvest yields does not necessarily translate into the same effects on grain prices (e.g. Mauelshagen 2010). Hoskins (1964, 1968), and many scholars of this generation, envisioned a weak and inconsistent climate signal in grain price data. De Vries (1980) anticipated a weaker link between climate and grain prices than one would expect from climate impacts on harvests. Pfister (1988) was of the opinion that while short-term grain price variations largely were climate driven, in the long-run grain prices were more closely linked to the economic development and trade patterns than to agricultural productivity. The most prevailing view today appears to be that climate variations influenced year-to-year and perhaps also decade-to-decade grain price variability, but played little role over longer timescales (see e.g. Kelly and Ó Gráda 2014a, b).

It is notable that most studies suggesting limited climate influences on the longterm grain price development have used detrended grain prices, to remove inflation, in such a way that any low-frequency price variability was removed too. This procedure has precluded the detection of relationships between climate variability and grain price volatility at longer timescales. Esper et al. (2017) detrended grain price data in a way that preserved low-frequency information. They retained multi-decadal trends in grain prices across early modern Europe and showed that much of these lower frequency variations could be explained by temperature variability.

\subsection{Solar variability and grain prices in early modern Europe}

The notion that the quasi-cyclic variations in solar radiation (Sect. 3.3; "Appendix 1") affect agricultural productivity, reflected in grain prices, has a long history. An anticorrelation between sunspot numbers and wheat prices was originally proposed by Herschel (1801): for the period 1646-1755, he identified five periods with low sunspot numbers and higher wheat prices and five periods with high sunspot numbers and lower wheat prices. This led Herschel (1801) to conclude that fewer sunspots resulted in poorer climate conditions for wheat and therefore triggered higher prices. Subsequent work by Carrington (1863) and Poynting (1884), however, failed to confirm the sunspot-grain price relationship proposed by Herschel (1801). Nevertheless, other studies reported such associations in India through solar forcing of the monsoon precipitation (e.g. Jevons 1878, 1879; Chambers 1886). Many researchers have subsequently analysed the links between sunspot variability and grain yields and prices, with various results, though mostly referring to short time-spans [see, for instance, King et al. (1974), Harrison (1976), Garnett et al. (2006)].

Several relatively recent studies have apparently supported the original findings by Herschel (1801). Pustil'nik and Din (2004) compared periodicities in English wheat prices from 1249-1702 with the length of measured solar cycles over 
the period 1700-2000. They relate an observed $\sim 10$-year wheat price cycle to the prevailing 11-year sunspot cycle. Using 22 European wheat price series covering 1590-1702, Pustil'nik and Din (2009) reported a north-south dipole pattern in solar cycle effect on wheat prices: prices in northern Europe being higher during solar minima, whereas prices in southern Europe being higher during solar maxima, and no sensitivity for large parts of central Europe.

However, claims of sunspot-grain price relationships have been contested for an apparent lack of statistical stringency. Love (2013) critically tested the proposed associations by employing three separate statistical methods considering wheat prices from London and the USA. He showed the relationships to be statistically insignificant when using methods that fully take auto-correlation into account. Furthermore, Love (2013) highlighted that studies reporting significant effects of the $\sim 11$-year sunspot cycle on grain price series have pre-filtered the data in a way that an over-fit is obtained (see further discussion in Sect. 5.3).

\subsection{Objectives}

The need for additional research on the relationship between climate variability and grain prices was recently highlighted by Camenisch and Rohr (2018). In particular, we have identified the following limitations of most previous climate-grain price studies: (1) The use of relatively small price data sets, typically representing only limited regions of Europe. (2) A focus on wheat prices and omission of other grain types. (3) The use of high-pass filtered grain price data, precluding detection of possible low-frequency signals. (4) Employing either instrumental data, covering a short time-span, or proxy-based climate reconstructions covering a longer timespan. (5) Assessing the climate influence on grain prices for a single season only.

The objective of this article is to fill some of these research gaps by: (a) studying, with identical methods, the direct effects of climate variability as well as the indirect effects of solar variability on the same unprecedentedly large price data set containing all four grain types (barley, oats, rye, and wheat). (b) Employing instrumental data and proxy-based reconstructions of temperature and precipitation/drought for both the annual mean and summer season. (c) Exploring the climate-grain price relationships at different frequencies with and without lags. (d) Analysing possible common periodicities in grain prices and climate and/or solar variability. By doing so, we revisit the grain price-climate relationships in a holistic and methodically more rigorous way than hitherto attempted. Our focus is entirely on the long-term relationship between grain prices and climate (and solar) variability as modern research has proven the high-frequency (inter-annual) climate-grain price relationship beyond doubt, whereas the long-term relationship is contested though reported to be actually even stronger by Esper et al. (2017).

We restrict our analysis to the 1500-1800 period. The decreasing number of available grain price series prior to $c$. 1500, and increasing data gaps, preclude robust statistical analysis further back in time. Furthermore, a large proportion of grain price series end $c .1800$ at approximately the same time as agricultural modernisation, increasing long-distance trade, improved transport infrastructure, and 
rapid urbanisation occurred. Already Beveridge (1921) found that the Thirty Years' War (1618-1648) period and, to a lesser extent, the period following the French Revolution (1789) resulted in a decoupling of grain prices from climate variability. This was empirically confirmed by Esper et al. (2017). We will therefore in this study investigate the effects of excluding these two periods from the analysis.

\section{Materials and method}

\subsection{Grain price data}

Generations of scholars have through meticulous archival work collected and published long grain price series. Notable early achievements include Rogers (1887) for England, Elsas (1936-1949) for Germany, Hauser (1936) for France, Posthumus (1946-1964) for the Netherlands, Pelc (1937) for Poland, and Hamilton (1934, 1947) for Spain. The majority of the published price series are now digitised and made publicly available in the Allen-Unger Global Commodity Prices Database (Allen and Unger 2019). We collected all barley, oats, rye, and wheat price series from this database, supplemented by additional series digitised by Esper et al. (2017), having less than $20 \%$ years with gaps over the 1546-1650 period in common for all grain price series. Reflecting the relative importance of different grain types for the early modern grain market, our data set consists of 10 price series for barley, 7 for oats, 14 for rye, and 25 for wheat across western and central Europe (Table 1; Fig. 1).

For series with more than one value per year, the mean was calculated to obtain an annual average. ${ }^{5}$ Missing values in a grain price series were infilled using the (standardised) average price from other locations within the same grain price cluster (see Sect. 3.4). ${ }^{6}$ To allow for an assessment of climatic forcing of the grain prices, it is necessary to first remove the presence of long-term inflation and volatility trends in such a way that low-frequency variability, potentially related to climate variations, is preserved. A data adaptive power transformation (Cook and Peters 1997) was applied to minimise volatility changes related to price level, and a cubic smoothing spline (Cook and Peters 1981) with a 50\% frequency-response cut-off equal to 300years was used to remove long-term inflation trends from the price series. The suitability of these methods for analysing environmental forcing in grain prices has been demonstrated by Esper et al. (2017) and confirmed by Ljungqvist et al. (2018). The price series of barley, oats, rye, and wheat were finally divided into regional groups by employing a hierarchical cluster analysis (see Sect. 3.4). The time-series of the

\footnotetext{
${ }^{5}$ In this study, we work with calendar years (i.e. January-December) and not with harvest years (i.e. harvest to harvest). Regarding the grain price cycle over the year, see in particular McCloskey and Nash (1984) and Claridge and Langdon (2011) about the medieval period and Bateman (2015) about the early modern period.

6 The variance adjustment and infilling of missing values as well as the adaptive power transformation and 300-year filtering were conducted with the open-source program ARSTAN (version ARS41dxp) (Cook and Krusic 2005).
} 


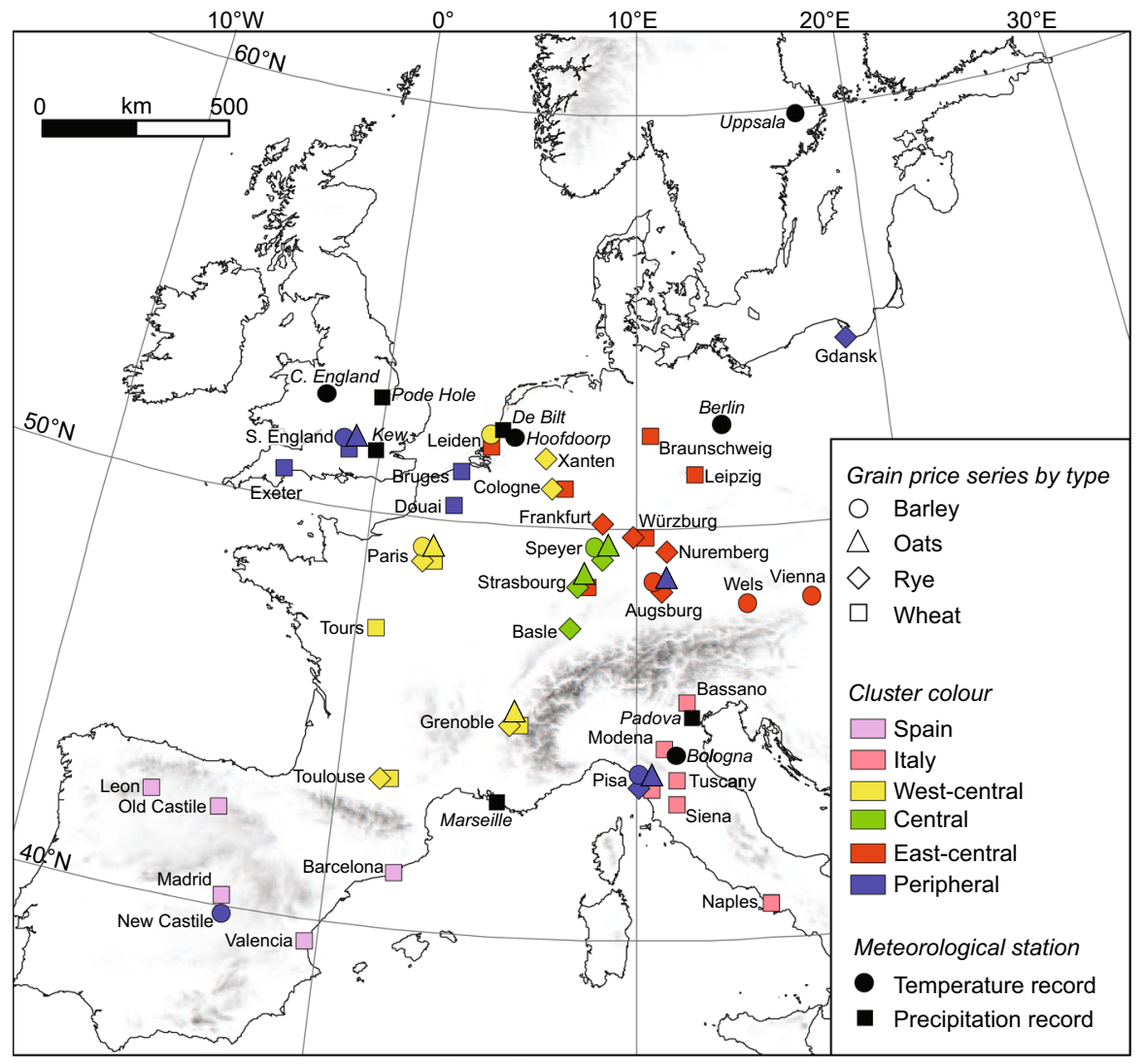

Fig. 1 Location of the included grain price data (coded after grain type and cluster assignment) as well as the location of the instrumental temperature and precipitation station records. For symbols and colours, see the legend

grain price clusters, for each grain type, are shown together with the mean for each grain type over the 1500-1800 period in Fig. 2.

\subsection{Temperature and hydroclimate data}

Continuous series of meteorological climate data are available from numerous locations in Europe since the mid-eighteenth century (Jones 2001), although a few temperature and precipitation records, though with gaps, extend back to the late seventeenth century (Briffa et al. 2009). We have included five temperature and five precipitation series starting prior to 1750 (Table 2). Annually resolved palaeoclimate reconstructions are employed to assess the influence of climate variability on grain prices over the entire 1500-1800 period. For summer (June-August) temperature, we use the reconstruction by Luterbacher et al. (2016) as updated by Ljungqvist et al. (2019). This reconstruction is derived from tree-ring data and historical 
Table 1 The 56 grain price series included in this study for the four grain types with location, the covered period, missing values ('gaps') in the common period 1546-1650 (in percent), cluster assignment, and data source

\begin{tabular}{|c|c|c|c|c|}
\hline Location & Period & Gaps & Cluster & Source \\
\hline \multicolumn{5}{|l|}{ Barley (10 series) } \\
\hline Augsburg & $1417-1820$ & 2.9 & East-central & Elsas (1936-1949) \\
\hline Leiden & $1392-1710$ & 3.8 & West-central & Posthumus (1946-1964) \\
\hline New Castile & $1504-1750$ & 17.4 & Peripheral & Hamilton (1934) \\
\hline Paris & $1520-1820$ & 1.0 & West-central & Hoffman (1996) \\
\hline Pisa & $1548-1818$ & 2.9 & Peripheral & Malanima (1976) \\
\hline Southern England & $1300-1699$ & 11.4 & Peripheral & Rogers (1887) \\
\hline Speyer & 1514-1799 & 20.0 & Central & Elsas (1936-1949) \\
\hline Strasbourg & $1386-1875$ & 1.0 & Central & Hanauer (1878) \\
\hline Vienna & 1469-1800 & 7.6 & East-central & Pribram (1938) \\
\hline Wels & $1471-1768$ & 18.1 & East-central & Pribram (1938) \\
\hline \multicolumn{5}{|l|}{ Oats (7 series) } \\
\hline Augsburg & $1455-1820$ & 1.0 & Peripheral & Elsas (1936-1949) \\
\hline Grenoble & $1527-1676$ & 4.8 & West-central & Hauser (1936) \\
\hline Paris & $1520-1788$ & 1.0 & West-central & Hoffman (1996) \\
\hline Pisa & $1553-1818$ & 11.4 & Peripheral & Malanima (1976) \\
\hline Southern England & $1300-1702$ & 1.9 & Peripheral & Rogers (1887) \\
\hline Speyer & 1517-1799 & 14.3 & Central & Elsas (1936-1949) \\
\hline Strasbourg & $1386-1875$ & 5.7 & Central & Hanauer (1878) \\
\hline \multicolumn{5}{|l|}{ Rye (14 series) } \\
\hline Augsburg & $1500-1800$ & 2.9 & East-central & Rahlf (1996) \\
\hline Basle & $1501-1797$ & 1.0 & Central & Hanauer (1878) \\
\hline Cologne & $1531-1787$ & - & West-central & Ebeling and Irsigler (1976) \\
\hline Frankfurt & $1350-1800$ & 18.1 & East-central & Elsas (1936-1949) \\
\hline Gdansk & $1538-1815$ & 8.6 & Peripheral & Pelc (1937) \\
\hline Grenoble & $1501-1781$ & 3.8 & West-central & Hauser (1936) \\
\hline Nuremberg & $1427-1671$ & - & East-central & Bauernfeind et al. (2001) \\
\hline Paris & $1520-1788$ & 9.5 & West-central & Hoffman (1996) \\
\hline Pisa & $1550-1818$ & 7.6 & Peripheral & Malanima (1976) \\
\hline Speyer & $1516-1815$ & 12.4 & Central & Elsas (1936-1949) \\
\hline Strasbourg & 1386-1875 & 1.9 & Central & Hanauer (1878) \\
\hline Toulouse & $1512-1792$ & - & West-central & Frêche and Frêche (1967) \\
\hline Würzburg & $1500-1799$ & 3.8 & East-central & Elsas (1936-1949) \\
\hline Xanten & $1500-1800$ & - & West-central & Rahlf (1996) \\
\hline \multicolumn{5}{|l|}{ Wheat (25 series) } \\
\hline Barcelona & $1533-1808$ & - & Spain & Feliu (1991) \\
\hline Bassano & 1501-1799 & 15.2 & Italy & Lombardini (1963) \\
\hline Braunschweig & $1513-1800$ & - & East-central & Oberschelp (1986) \\
\hline Bruges & $1348-1800$ & 6.7 & Peripheral & Verlinden (1959) \\
\hline Cologne & $1531-1796$ & - & East-central & Ebeling and Irsigler (1976) \\
\hline Douai & 1329-1789 & - & Peripheral & Hauser (1936) \\
\hline
\end{tabular}


Table 1 (continued)

\begin{tabular}{|c|c|c|c|c|}
\hline Location & Period & Gaps & Cluster & Source \\
\hline Exeter & 1316-1816 & 14.3 & Peripheral & Mitchell (1971) \\
\hline Grenoble & $1501-1780$ & 2.9 & West-central & Hauser (1936) \\
\hline Leiden & 1392-1792 & 3.8 & East-central & Posthumus (1946-1964) \\
\hline Leipzig & $1564-1820$ & 8.6 & East-central & Elsas (1936-1949) \\
\hline Leon & $1506-1650$ & 5.7 & Spain & Hamilton (1934) \\
\hline Madrid & 1501-1799 & 9.5 & Spain & Hamilton $(1934,1947)$ \\
\hline Modena & $1458-1705$ & - & Italy & Basini (1974) \\
\hline Naples & $1550-1803$ & 14.3 & Italy & Faraglia (1878) \\
\hline Old Castile & $1506-1650$ & 5.7 & Spain & Hamilton (1934) \\
\hline Paris & $1431-1870$ & - & West-central & Hoffman (1996) \\
\hline Pisa & $1548-1818$ & 2.9 & Italy & Malanima (1976) \\
\hline Siena & $1546-1765$ & - & Italy & Parenti (1942) \\
\hline Southern England & 1300-1914 & - & Peripheral & Rogers (1887) \\
\hline Strasbourg & $1342-1875$ & 4.8 & East-central & Hanauer (1878) \\
\hline Toulouse & 1486-1792 & - & West-central & Frêche and Frêche (1967) \\
\hline Tours & $1431-1788$ & - & West-central & Hauser (1936) \\
\hline Tuscany & 1309-1859 & - & Italy & Pribram (1938) \\
\hline Valencia & 1413-1789 & 1.9 & Spain & Hamilton (1936) \\
\hline Würzburg & $1500-1799$ & 19.0 & East-central & Elsas (1936-1949) \\
\hline
\end{tabular}

The full period of coverage of each grain price series is shown even though we only include data for the 1500-1800 period in this study

Table 2 Instrumental station records of temperature and precipitation included in this study

\begin{tabular}{lrrll}
\hline Station record & Start & Long. & Lat. & Source \\
\hline Temperature series & & & & \\
Berlin, Germany $^{\mathrm{a}}$ & 1701 & 13.40 & 52.60 & Jones (2001) \\
Bologna, Italy & 1716 & 11.34 & 44.49 & Camuffo et al. (2016, 2017) \\
Central England, Great Britain & 1659 & -1.50 & 51.50 & Manley (1974) \\
De Bilt, The Netherlands & 1706 & 5.18 & 52.11 & Jones (2001) \\
Uppsala, Sweden & & 17.63 & 59.86 & Moberg and Bergström (1997) \\
Precipitation series & 1722 & & & \\
Hoofdoorp, The Netherlands & 1735 & 4.69 & 52.31 & Jones (2001) \\
Kew, Great Britain & 1697 & -0.28 & 51.47 & Jones (2001) \\
Marseille, France & 1749 & 5.37 & 43.30 & Jones (2001) \\
Padova, Italy & 1725 & 11.88 & 45.41 & Jones (2001) \\
Pode Hole, Great Britain & 1726 & -0.20 & 52.78 & Jones (2001) \\
\hline
\end{tabular}

The locations of the ten instrumental station records are shown in the map in Fig. 1

a The Berlin temperature series contains numerous gaps during the eighteenth century: $23 \%$ of the months have missing values between 1701 and 1800 .

b Observations from Uppsala are lacking between June 1732 and December 1738 and are instead derived from Risinge $170 \mathrm{~km}$ to the south-west, and between June 1742 and April 1745, when they are instead derived from Bettna $120 \mathrm{~km}$ to the south-west. The Uppsala series also contain other, shorter, gaps when the values are obtained from other stations (Moberg and Bergström 1997) 
documentary evidence, resolved at a $5^{\circ} \times 5^{\circ}$ grid, of which we extracted the spatial average representing $55^{\circ} \mathrm{N}-35^{\circ} \mathrm{N}$ and $10^{\circ} \mathrm{W}-20^{\circ} \mathrm{E}$. We are only using this European average, rather than the individual $5^{\circ} \times 5^{\circ}$ grid cells, considering the very high correlation grid-cell inter-correlation (mean $r=0.71$; median $r=0.77$ ). For annual mean temperature, we use the documentary-based reconstructions for Central Europe by Glaser and Riemann (2009) (henceforth GR09) and Dobrovolný et al. (2010) (henceforth D10). ${ }^{7}$

For variations in growing season drought conditions, we employ the Old World Drought Atlas (Cook et al. 2015). This tree-ring-based reconstruction reflects June-August soil moisture conditions in the form of self-calibrated Palmer Drought Severity Index (scPDSI) values presented on a $0.5^{\circ} \times 0.5^{\circ}$ grid across Europe. Since we cannot exactly mimic the coverage corresponding to our grain price clusters, we calculate the spatial average of the drought index for three regions, broadly corresponding to different hydroclimate regimes, namely west-central Europe $\left(55^{\circ}-45^{\circ} \mathrm{N}\right.$, $\left.10^{\circ} \mathrm{W}-10^{\circ} \mathrm{E}\right)$, east-central Europe $\left(55^{\circ}-45^{\circ} \mathrm{N}, 10^{\circ} \mathrm{E}-20^{\circ} \mathrm{E}\right)$, and Mediterranean Europe $\left(45^{\circ}-35^{\circ} \mathrm{N}, 10^{\circ} \mathrm{W}-20^{\circ} \mathrm{E}\right)$.

\subsection{Solar variability data}

The intensity of sunlight emitted by the Sun varies over time, influencing Earth's climate, but solar irradiance has only been measured with satellite observations since 1978. However, it is possible to estimate solar variability prior to that considering the changing sunspot numbers as indicator of solar activity. Sunspots are areas of lower temperature in the photosphere, or 'surface', of the Sun appearing in differing numbers with a $\sim 11$-year cycle. Superimposed on this $\sim 11$-year cycle are longer cycles of solar activity (see "Appendix 1" for further details).

Sunspot abundances are typically counted in two ways: the number of individual spots or the number of groups (i.e. sunspot clusters) containing spots. The former can be ambiguous, as some observers counted more spots than others due to different types of equipment or personal preferences in separating closely spaced spots. However, the number of individual sunspots and the sunspot group number have a proportional relationship (correlating at $r=0.94$ over the period 1700-2015). Observation-based estimates of the annual sunspot group number extend back to 1610 (Svalgaard and Schatten 2016) and are employed in this study.

Prior to the invention of the telescope in 1608, estimates of solar activity rely on reconstructions based on cosmogenic radiocarbon $\left({ }^{14} \mathrm{C}\right)$ and beryllium isotopes $\left({ }^{10} \mathrm{Be}\right)$. They are produced by cosmic rays modulated by solar activity as well as by the geomagnetic field. The ${ }^{14} \mathrm{C}$ or ${ }^{10} \mathrm{Be}$ solar irradiance reconstructions show temporal discrepancies at inter-annual to decadal timescales, compared to observed sunspot group numbers, but consistent long-term variability (Fig. 2). We employ

\footnotetext{
7 The GR09 reconstruction has the annual temperature values smoothed to an 11-year mean and contains a gap at $1761-1765$.
} 

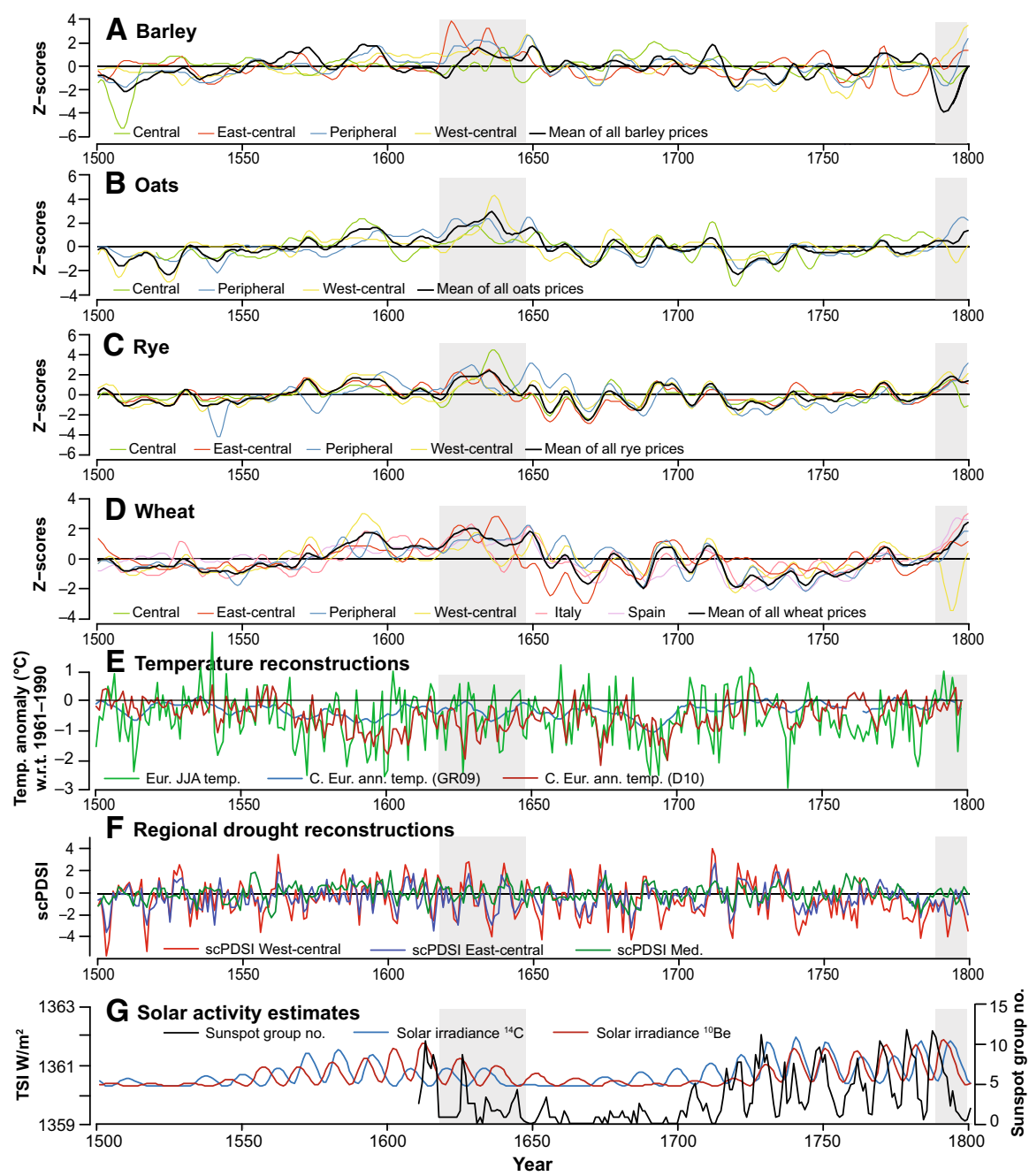

Fig. 2 Selection of analysed time-series: a-d Regional clusters of detrended and standardised grain price data, here 10-year smoothed for illustrative purposes only, displayed by grain type and showing the mean of all series of the same grain type. e Mean of the area $55^{\circ} \mathrm{N}-35^{\circ} \mathrm{N} / 10^{\circ} \mathrm{W}-20^{\circ} \mathrm{E}$ of the June-August temperature reconstruction by Luterbacher et al. (2016), as updated by Ljungqvist et al. (2019) (green), and the Central Europe annual mean temperature reconstructions by Glaser and Riemann (2009) (GR09, blue) and Dobrovolný et al. (2010) (D10, red). f Mean of the tree-ring reconstructed June-August selfcalibrated Palmer Drought Severity Index (scPDSI) by Cook et al. (2015) for west-central Europe $\left(55^{\circ}-\right.$ $\left.45^{\circ} \mathrm{N}, 10^{\circ} \mathrm{W}-10^{\circ} \mathrm{E}\right)$, east-central Europe $\left(55^{\circ}-45^{\circ} \mathrm{N}, 10^{\circ} \mathrm{E}-20^{\circ} \mathrm{E}\right)$, and Mediterranean Europe $\left(45^{\circ}-35^{\circ} \mathrm{N}\right.$, $10^{\circ} \mathrm{W}-20^{\circ} \mathrm{E}$ ). g Observed sunspot group numbers since 1610 (Svalgaard and Schatten 2016) and ${ }^{14} \mathrm{C}$ and ${ }^{10} \mathrm{Be}$ reconstructed total solar irradiance (Jungclaus et al. 2017). The periods corresponding to the Thirty Years' War (1618-1648) and following the French Revolution (1789) are grey-shaded

state-of-the-art total solar irradiance reconstructions at annual resolution published by Jungclaus et al. (2017). 

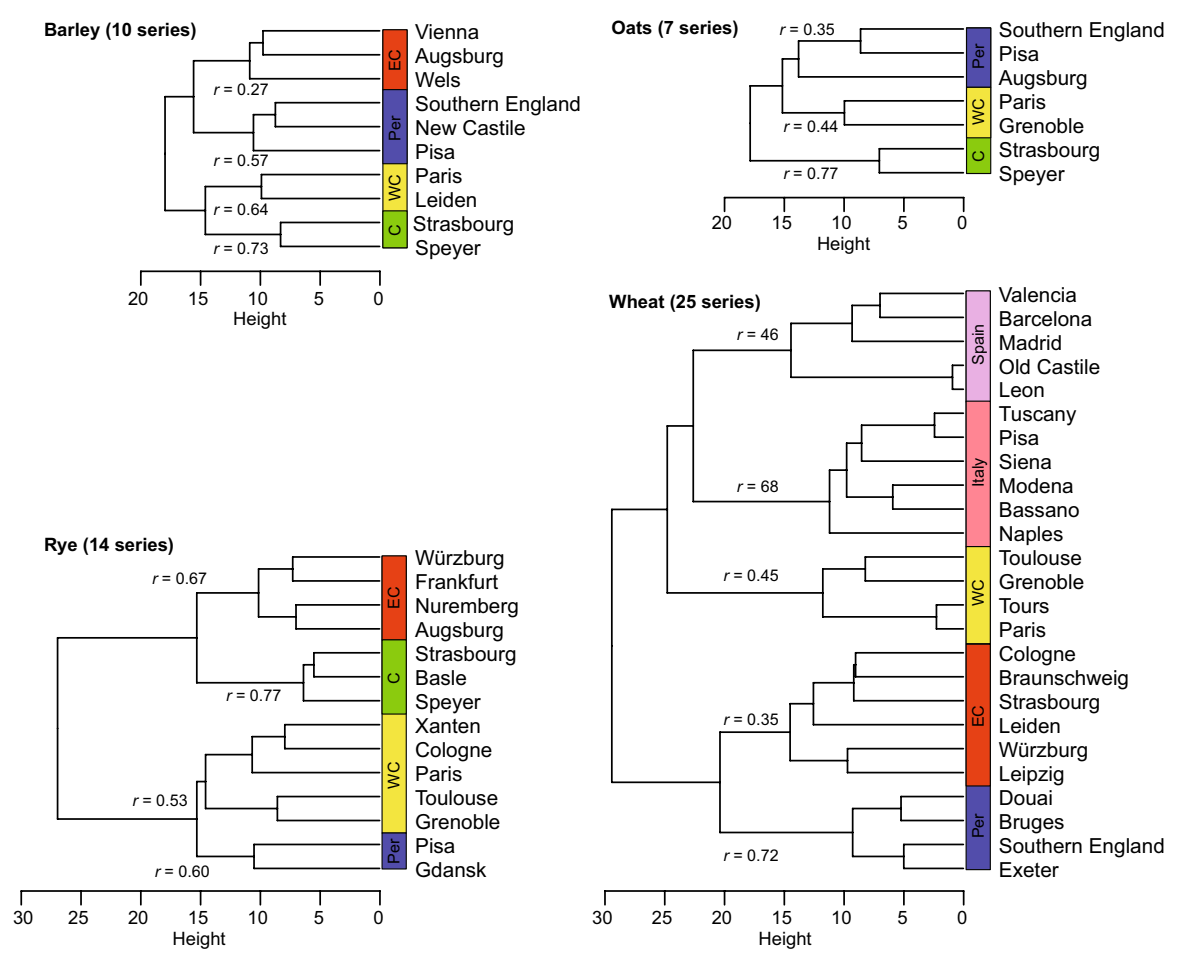

Fig. 3 Hierarchical cluster analysis of the price series for barley, oats, rye and wheat using the Ward's method for agglomeration and the Euclidean distance. 'Height' refers to the inter-cluster distance. The mean correlation between grain price series within each cluster over the common period 1546-1650 is shown. Cluster abbreviations: $C$ central; $E C$ east-central; Per peripheral; $W C$ west-central

\subsection{Cluster analysis and intra-cluster correlations}

Since many of our 56 grain price series show a strong co-variance, we employ a method to cluster similar series on the basis of quantitative algorithms. We applied a hierarchical cluster analysis to the grain price series over their common period 1546-1650, for each grain type separately, to group and subsequently average similar series (Fig. 3). Thereby, we reduce the number of series, increase the signalto-noise ratio, and limit the spatial degrees of freedom problem (for the latter, see Sect. 3.5). We considered the Euclidean (straight line) distance norm and the method for cluster agglomeration based on Ward (1963). ${ }^{8}$ After the dendrogram is calculated, a cut is made of the 'tree' and this defines the clusters. We chose a cut corresponding to a large jump in the inter-cluster distances. The detected clusters

\footnotetext{
${ }^{8}$ We use the hclust function from the $\mathbf{R}$ base library 'stats' (R Core Team 2020). Two methods are commonly referred to as the 'Ward's method'-we use the 'Ward.D' method. It is distinct from the original Ward's method by not squaring the distances used during agglomeration; see Murtagh and Legendre (2014) for a discussion of this.
} 
correspond closely with major geographic regions in Europe (see Fig. 1). In all 16 cluster mean time-series were formed: four each for barley and rye, three for oats, and five for wheat (Fig. 3).

Cluster analysis is a data-driven approach to define regions of co-variance and grouping data independently of a priori assumptions of geographical co-variability patterns. Thus, the grouping of the grain price series is entirely determined by the co-variance among the different series. Such an approach is relatively uncommon in economic history, though it has many advantages as discussed in Sect. 5.1, but has predecessors in Chilosi et al. (2013) and Studer (2015) employing principal component analysis to detect regions of high grain price co-variability.

The different grain price cluster series are highly correlated, as are the individual grain price series, except the Barley Central cluster (consisting only of data from Speyer and Strasbourg). Furthermore, the Peripheral and West-central barley clusters, Central oats cluster, Central rye cluster, and West-central wheat price cluster exhibit inhomogeneities (i.e. unrealistically low prices) following the period after the French Revolution (1789).

\subsection{Correlation analysis and significance estimation}

In this study, we make extensive use of correlation analysis along with various spectral analysis methods. The conclusions from such analyses depend not on the magnitude of the result but, rather, its magnitude relative to the significance level. We therefore put effort into using the most appropriate methods for establishing significance levels of all results we present. Correlation analysis in this article refers to calculations of the Pearson correlation coefficients. However, we also tested the use of Spearman's rank correlation, potentially more suitable for correlations between time-series with nonlinear relationships, but found only minor differences between the two methods.

We require that results are significant at the $p_{\text {crit }}=0.05$ level or better. The significance of the correlations was determined in different ways: using a $t$ test or using synthetic data based on a phase-scrambling technique (Schreiber and Schmitz 2000). The standard $t$ test does not take serial correlations of the data into account as it assumes that the number of degrees of freedom is almost the same as the number of data points $(n-2)$. For auto-correlated data, this assumption is broken and the $t$ test can be too optimistic-i.e. the probability of getting a false positive is higher than expected.

The effect of serial correlations is systematically included in the phase-scrambling technique, where the significance is estimated by directly counting the rate of false positives using synthetic data. The synthetic data are generated by random scrambling of the Fourier phases, and the resulting time-series has no causal relationship with the original series, but its auto-correlative structure is the same (Prichard and Theiler (1994); see also Christiansen et al. (2009) for an example of the implementation of this). The synthetic data are used to build distributions of the sampled correlations under the null-hypothesis of no correlation. If the detected 
correlation is an outlier from this synthetic distribution, the result is considered significant.

While the phase-scrambling technique is used in general throughout the article, we also use the parametric $t$ test. When considering correlations between 10-year filtered data, which are strongly auto-correlated by nature, we used a modification of the $t$ test introduced by Bartlett (1935) (see "Appendix 2"), based on estimating the effective degrees of freedom used in the $t$ test on the basis of the auto-correlation of the two series at lag 1 (see "Appendix 3"). More precisely, the reduced number of degrees of freedom is $n\left(1-\alpha_{1} \alpha_{2}\right) /\left(1+\alpha_{1} \alpha_{2}\right)$, where $\alpha_{1}$ and $\alpha_{2}$ are the auto-correlations at lag 1 of series 1 and 2 , respectively. Note that this procedure is strictly only valid if the series in question behave like AR1-processes.

For proper statistical correlation analysis, it is not only necessary to take the auto-correlation of single series (i.e. across time) into account, but also acknowledge effects from spatial correlations (see Christiansen and Ljungqvist (2017) and references therein). It can be tempting, but incorrect, to interpret multiple significant correlations as extra verification just because there are several of them in those cases where the series are inter-correlated. Significance testing methods that are able to deal with this include surrogate data testing (e.g. Thejll 2001; Christiansen 2013) as well as reducing the amount of data by aggregating similar time-series. To mitigate the spatial degrees of freedom problem, we have used the latter method by applying cluster analysis (Sect. 3.4) to the grain price series.

\subsection{Spectral analysis methods}

We employ spectral analysis methods to understand which periodicities are present in our data, if any, and whether similar periodicities exist in pairs of time-series. Thus, we calculate power density spectra as well as the coherency (sometimes labelled 'coherency-squared') of single series and pairs of series. A power density spectrum is essentially the amplitude of the Fourier transform of the auto-correlation function for a single series. Coherency is the amplitude of the Fourier transform of the cross-correlation between two series. We performed extensive testing on constructed pairs of time-series (see "Appendix 4") of the ability of such analyses to detect known links; we have come to the conclusion that the above-mentioned analysis tools provide causality insights provided one only considers frequencyintervals (actually, periods $=1 / f$ ) where the power density is significant in both series in the presence of simultaneous significant coherence. Extensive testing (not shown) revealed that the imposition of data gaps, e.g. due to the omission of the Thirty Years' War (1618-1648), did not generate spectral artefacts, allowing us to use spectral methods assuming continuous data ${ }^{9}$. Significance levels of spectral analyses are established by repeatedly applying the same approaches to surrogate data that have similar spectral properties as the original data. The surrogate data are of the same length have the same mean, variance, and auto-correlative structure as

\footnotetext{
${ }^{9}$ We use the crossSpectrum function from the $\mathbf{R}$ library 'IRISSeismic' (Callahan et al. 2019).
} 


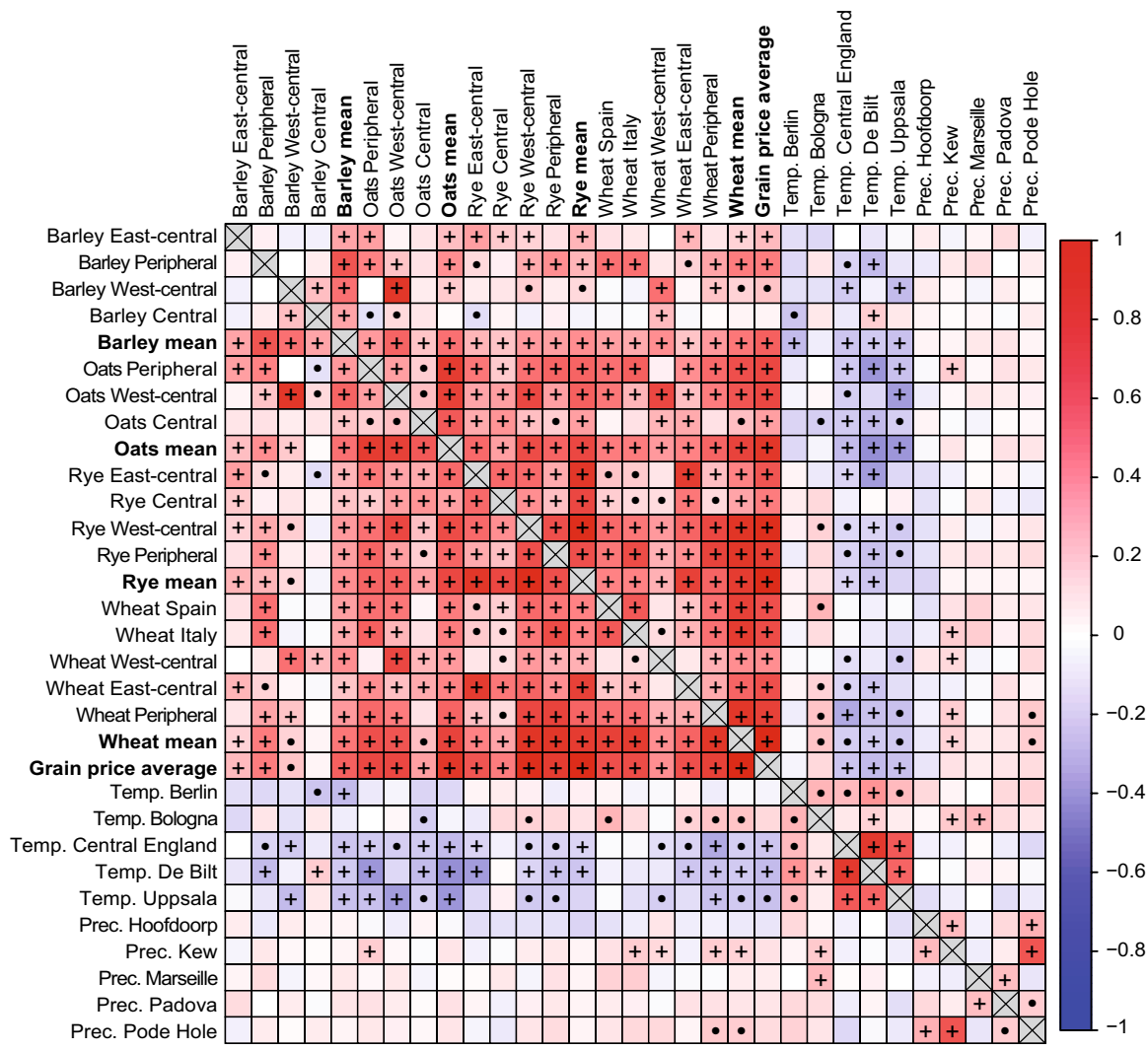

Fig. 4 Cross-correlation matrix between grain price clusters and instrumental annual mean temperature and precipitation data from the start of each instrumental series until 1800. The correlations between the different grain price clusters run from 1659, start year of the longest instrumental series, until 1800. Correlations significant at $p=0.05$ with a $t$ test are marked with a dot $(\cdot)$. Values also significant using the phase-scrambling test are marked with a plus sign $(+)$. Blue colours correspond to negative correlations (i.e. 'anti-correlations') and red colours to positive correlations

the original series. We performed 10,000 such surrogate data trials and estimated $p=0.05$ significance levels for different period.

\section{Results}

\subsection{The relationship between climate variability and grain prices}

In this section, we analyse the relationship between instrumental and reconstructed temperature and hydroclimate variability on the grain price variations. Figures 4, 5, and 6 show the individual pair-wise correlations for all combinations while the histograms in Fig. 8 summarise the distribution of the correlations between grain price 


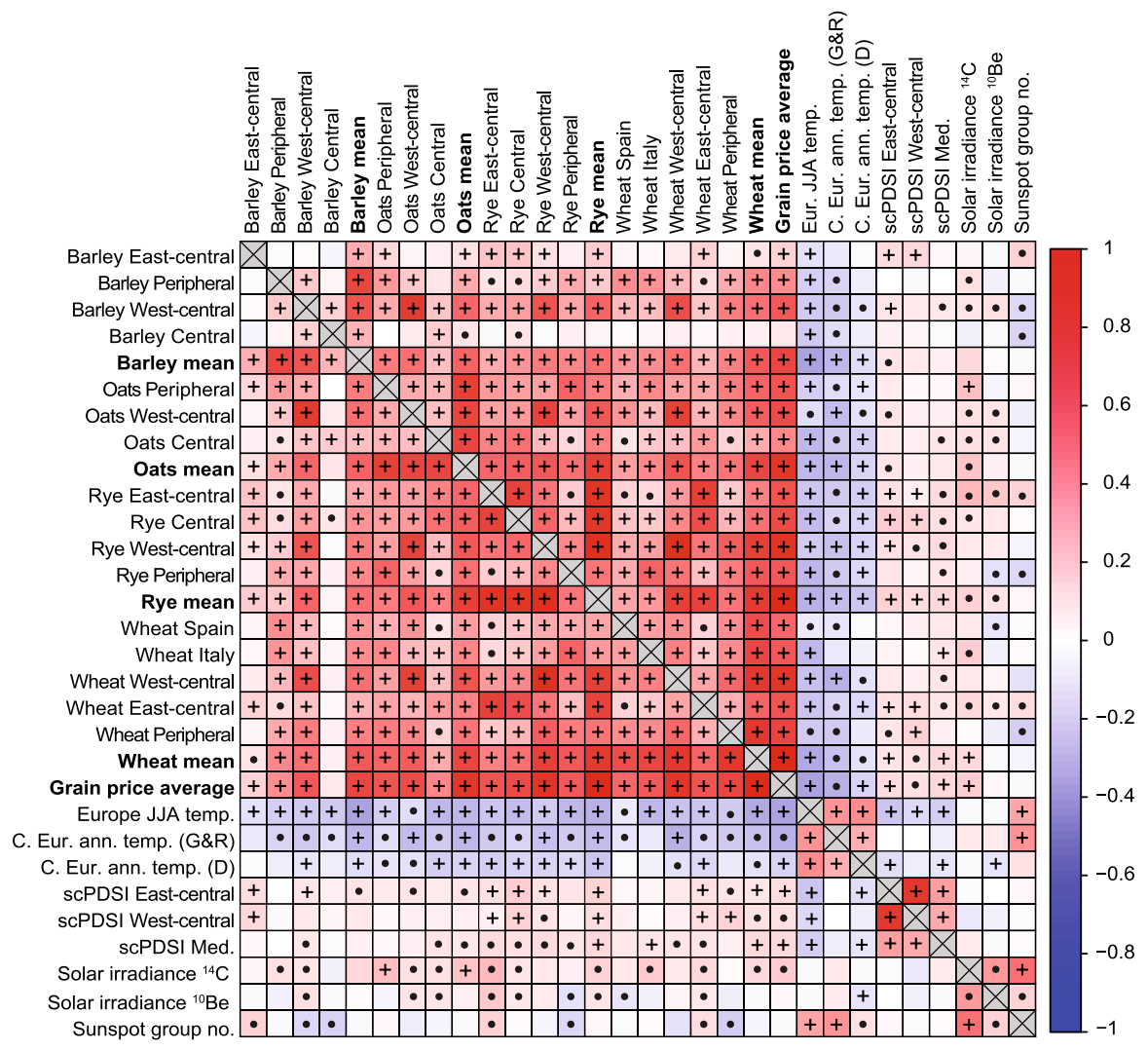

Fig. 5 Cross-correlation matrix for grain price clusters, reconstructed temperature and drought series, and solar activity series over the period 1500-1788 (and excluding the Thirty Years' War, 1618-1648) with grain prices lagging climate and solar forcing data 1 year. Correlations significant at $p=0.05$ with a $t$ test are marked with a $\operatorname{dot}(\cdot)$. Values also significant using the phase-scrambling test are marked with a plus sign (+). Blue colours correspond to negative correlations (i.e. 'anti-correlations') and red colours to positive correlations

data and different climate data sets. Furthermore, Tables 4, 5, and 6 in Appendix contain the correlation values and their significance.

\subsubsection{Correlations between instrumental climate data and grain prices}

The correlations between the grain price clusters and the instrumental series of annual mean temperature are in general negative (individual start date to 1800), which is best seen for Central England, De Bilt, and Uppsala, indicating that high grain prices correspond to low temperatures and vice versa (blue squares in Fig. 4). We found a modest average correlation of $r=-0.13$, with $29 \%$ of the correlations significantly negative using the phase-scrambling-based significance test (42\% using the $t$ test), demonstrating a real connection, especially for the two longest instrumental temperature series (Central England and De Bilt). Only the barley 


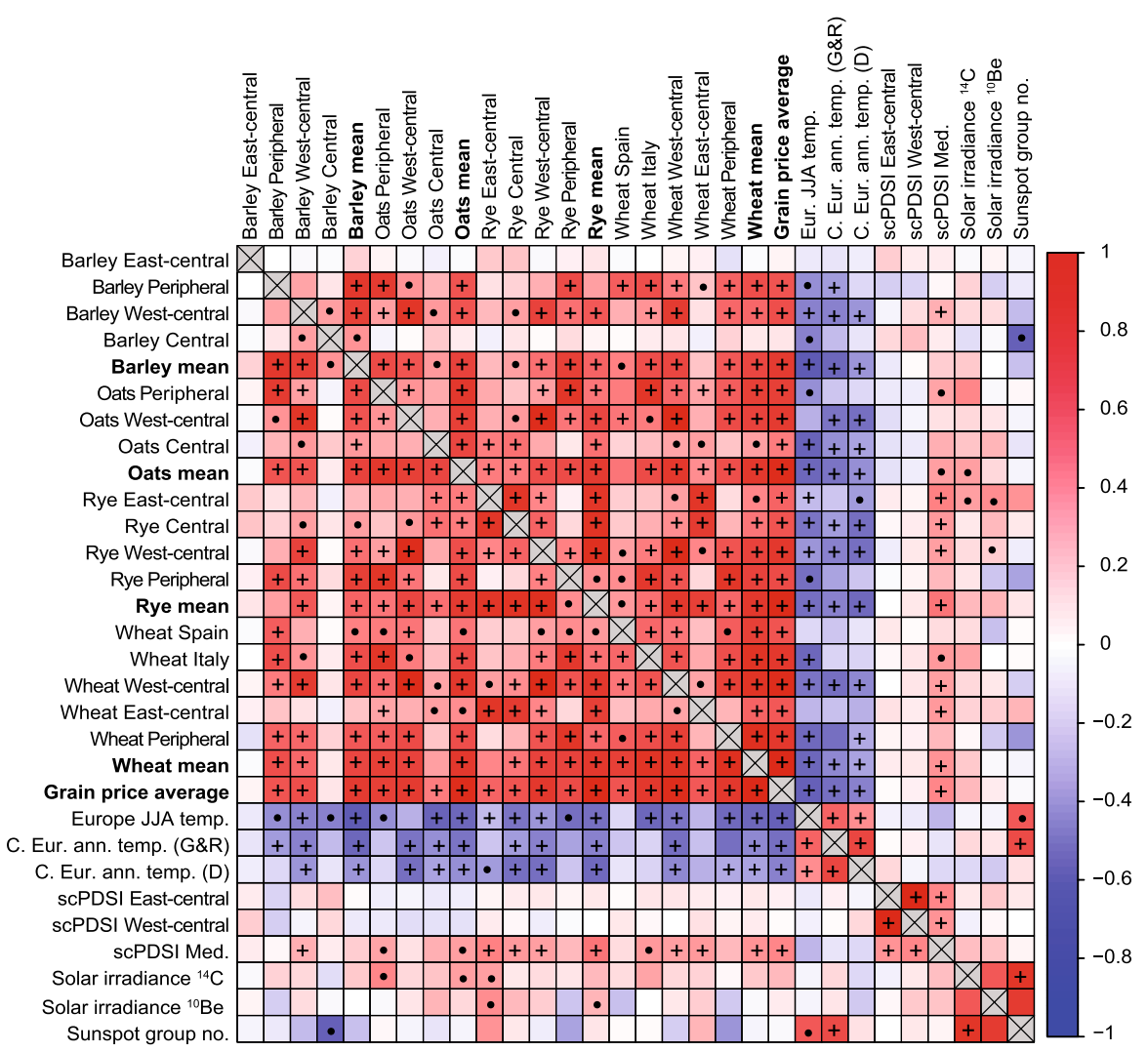

Fig. 6 Cross-correlation matrix for 10-year box-car filtered grain price clusters, and reconstructed temperature and drought series, and solar activity series over the 1500-1788 period (and excluding the Thirty Years' War period) in once-per-decade steps. Correlations significant at $p=0.05$ with a $t$ test are marked with a dot $(\cdot)$. Values also significant using the phase-scrambling test are marked with a plus sign (+). Blue colours correspond to negative correlations (i.e. 'anti-correlations') and red colours to positive correlations

and oat clusters correlate negatively with the Berlin temperature data, whereas all rye (except Rye central) and all wheat clusters correlate positively (i.e. high price $=$ high temperature) with the Bologna temperature data. Using June-August temperature data instead of the annual mean, the correlation coefficients are overall lower and less significant, except for De Bilt (Table 4 in Appendix). Similar results were obtained when extending the period of correlations between instrumental data and the barley and wheat price data to 1820 .

The correlations between the grain price clusters and annual precipitation are mainly weakly positive (i.e. high price $=$ high precipitation) though only $7 \%$ are significant considering the phase-scrambling-based significance test $(9 \%$ using the $t$ test) (Fig. 4; Table 4 in Appendix). Thus, only weak evidence is found for a real connection. Significant correlations are mainly obtained with the Kew, England, record, which is the longest precipitation series. Using June-August precipitation results in, 
on average, a more negative grain price-precipitation association, though less than $3 \%$ of the correlations are significant using the phase-scrambling-based significance test (5\% using the $t$ test) (see Table 4 in Appendix). Significant grain price-temperature and grain price-precipitation correlations are not only restricted to grain price clusters close to the location of the particular meteorological stations.

\subsubsection{Correlations between reconstructed climate data and grain prices}

We found negative correlations between all grain price clusters and all three temperature reconstructions over the 1500-1788 period (excluding the Thirty Years' War, 1618-1648). The average correlation is $r=-0.22$, and more than half (54\%) of these are significant at $p=0.05$ using the phase-scrambling method $(86 \%$ with the $t$ test). The strongest correlations are obtained when using the June-August temperature reconstruction (Table 5 in Appendix). While a few correlations could be significant by chance, we emphasise that this general picture provides strong evidence for a real negative association between temperature and grain price. The stronger and more significant correlations using reconstructed data, compared to instrumental data, may result from the periods of analysis being much larger though the reconstructions potentially contain more noise.

The highest correlations between reconstructed temperature and grain prices are found either for grain type means or the grain price average including all 56 series $(r=$ -0.39 between the latter and reconstructed June-August temperature). We note a changing temperature sensitivity of the grain price series over time. For example, the correlations between temperature and grain price are generally stronger in the period prior to the Thirty Years' War (1500-1617) than in the period following the war (1649-1788). Beyond this temporal pattern, no clear geographical difference in the sensitivity of grain prices to temperature is apparent (see further discussion in Sect. 5.2).

The correlations between grain prices and reconstructed drought are weak and include only few significant correlations (less than 5\% using the phase-scrambling method) that could easily occur by chance. These drought-grain price correlations, albeit mainly insignificant, are in general positive (i.e. wetter climate conditions = high prices) and are in agreement with the positive (though also mainly insignificant) relationship between instrumental precipitation and grain prices (Sect. 4.1.1).

Grain price variations can be expected to lag climate variability as the price level responds to harvest size (see "Appendix 5"). Analysing the lag effect of climate on grain prices in the subsequent year, slightly higher correlations with temperatures are found (Fig. 5). The correlation reaches $r=-0.41$ between the average of all 56 grain price series and reconstructed June-August temperature. We find a bigger change, with stronger and more significant correlations, between grain prices and drought when considering a 1 year lag. Wetter years tend to result in higher grain prices the following year and vice versa. 
In all the analyses above, we excluded the Thirty Years' War (1618-1648) and the period following the French Revolution (1789). ${ }^{10}$ Including these two periods slightly decrease the correlations between temperature and grain price-in line with earlier findings by Esper et al. (2017). Finally, the 'Wheat Peripheral' cluster extending back to 1348 allows us to test the effects of having a $~ 150$-year longer period of overlap with reconstructed June-August temperature and drought data. However, using this longer period results in decreasing, rather than increasing, correlations.

\subsubsection{Decadal-scale correlations between climate and grain prices}

Using 10-year smoothed data, by applying 10-year box-car and spline filters, stronger climate-grain price correlations are obtained (Fig. 6; Table 6 in the Appendix). Here we focus on the 10-year box-car filtered data, considering that the auto-correlation structure is easier to account for and thus less complex to perform statistical testing for significance on (Appendix 2), though similar results are obtained using 10-year spline filtered data (Table 6 in Appendix). The larger correlations using smoothed data should only be interpreted with a simultaneous close look at how the significance levels change with the smoothing. Reducing the number of degrees of freedom increases the range of observed correlations even under the null-hypotheses of uncorrelated series. Indeed, the range of the correlations has increased but the number of significant correlations has in general remained constant. For the temperature-grain price correlations, the average correlation increases to $r=-0.42$ (compared to $r=-0.22$ for unsmoothed data), with $51 \%$ being significant (compared to $54 \%$ for unsmoothed data). However, the number of significant drought-grain price correlations increases slightly (from 5\% for unsmoothed data to $13 \%$ for smoothed data).

The presence of stronger, but still equally significant, correlations after 10-year low-pass filtering the data demonstrates that the climate-grain price relationship may not only be a result of high-frequency co-variability. This implies the presence of an important multi-decadal relationship. As with the annually resolved data, the highest correlations are obtained using the grain type mean or the grain price average of all 56 series. The latter correlates at $r=-0.63$ with reconstructed June-August temperature, $r=-0.55$ with the GR09 reconstructed annual mean temperature, and $r=-0.49$ with the D10 reconstructed annual mean temperature. The highest correlation obtained $(r=-0.66)$ is found between the barley price mean and reconstructed June-August temperature.

\subsubsection{Spectral and coherency analysis between climate and grain prices}

The spectral analysis reveals highly significant periodicities of $\sim 5$ years and weakly significant periodicities of $\sim 16$ years in the grain price data over the 1500-1788

\footnotetext{
${ }^{10}$ We did not exclude the period following the French Revolution (1789) when analysing instrumental temperature and precipitation data as it would have resulted in too short a length for many of the instrumental series to obtain significant correlations.
} 

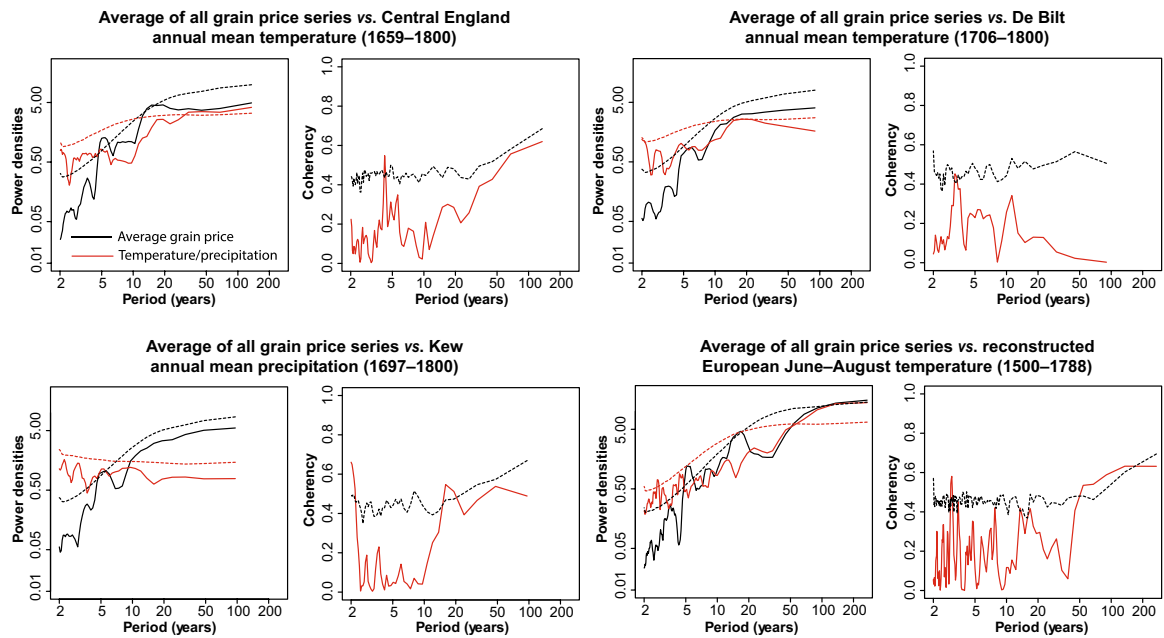

Average of all grain price series vs. Central European annual mean temperature by Glaser and Riemann (2009) (1500-1788)
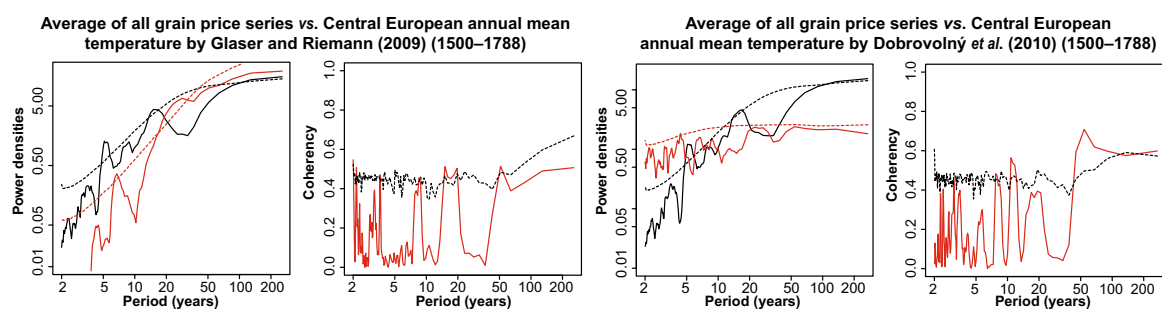

Fig. 7 Spectral power density and coherency analyses between climate data and average grain prices over the 1500-1788 period with the Thirty Years' War (1618-1648) period excluded. Stippled lines indicate the significant at $p=0.05$ significance levels determined by surrogate-data methods based on generating unrelated series with the same autocorrelation at lag 1 as the original series. 10,000 surrogate data trials were performed, and the $p=0.05$ significance determined at each period along the $x$-axis for both spectral power and coherency

period (Fig. 7). Another, though barely significant, grain price oscillation of $\sim 50$ years is recorded. The instrumental climate data reveal no periodicities on shorter timescales and are too short to robustly detect periodicities at longer timescales. However, the Central England temperature series shows spectral power on multidecadal timescales, which is difficult to interpret given the limited length of the series, and the De Bilt temperature series shows a $\sim 20$-year periodicity bordering significance. The three temperature reconstructions reveal spectral power on multi-decadal timescales. Otherwise, only weak periodicities of $\sim 3$ years are found in the June-August temperature reconstruction, of $\sim 7$ years in the GR09 annual mean temperature reconstruction, and of $\sim 4$ years in the D10 annual mean temperature reconstruction.

Coherency analysis reveals a wide range of common periodicities between the grain price data and the climate series. The most prevailing ones are seen at $\sim 4$ years, $\sim 20$ years, and $\sim 50$ years (Fig. 7). In addition, a common periodicity with the grain prices of $\sim 8-9$ years as well as $\sim 12$-years is recorded in the D10 annual 

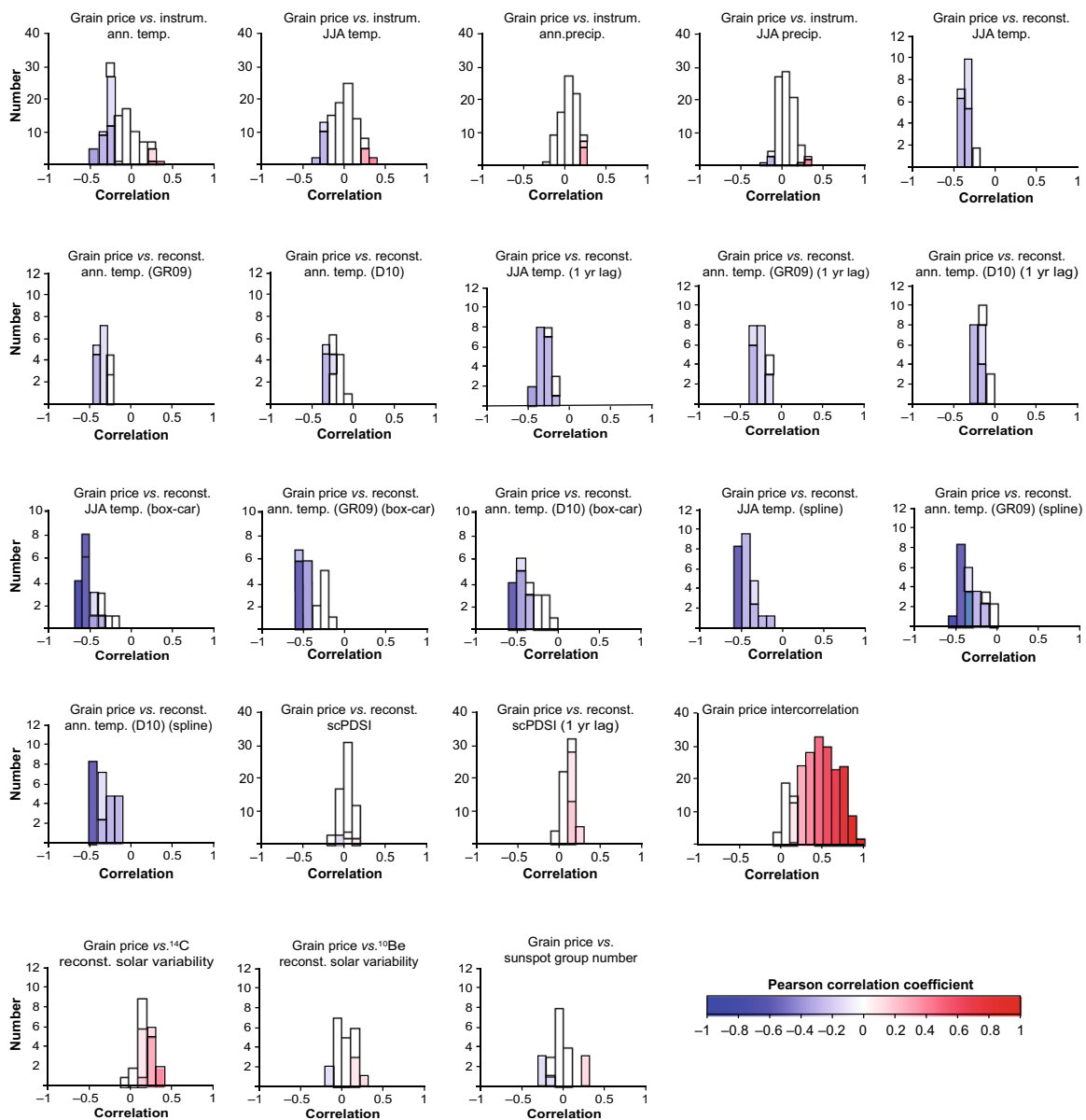

Fig. 8 Histograms showing the distribution of correlations. Coloured bars denote significant correlations using the phase-scrambling technique and transparent bars denote correlations significant only when using the standard $t$ test. The colour scheme follows the matrices in Figs. 4, 5 and 6

mean temperature reconstruction. We only consider as significant coherence those periodicities that are significant in both series in the power density spectrum (see Sect. 3.6). Thus, the absence of simultaneous significant power in the power density spectra of climate and grain price series, and their coherence, implies that results regarding coherency shown in Fig. 7 must be interpreted with caution. It also means that the climate-grain price relationship is of an episodic rather than periodic nature.

\subsubsection{Summary of climate-grain price relationships}

To conclude, overall similar correlations are obtained between grain prices and the (relatively short) instrumental series as well as between grain prices and proxybased climate reconstructions (for the distribution of the different correlations; 
see the histograms in Fig. 8). Negative correlations (i.e. colder $=$ high prices and vice versa), which to a large extent are significant, are found between grain prices and temperature regardless of whether instrumental or reconstructed data are used. Mainly insignificant and mostly positive correlations are found between grain prices and hydroclimate-again regardless of whether instrumental precipitation or reconstructed data are employed. We emphasise the results using the conservative phasescrambling method to calculate significance as the common parametric $t$ test may spuriously overestimate the connection between grain price and climate, and could erroneously lead to a conclusion that a strong connection between grain price and temperature and hydroclimate exists (see Sect. 3.5).

We found the climate-grain price relationships not to be regionally restricted, but rather to be large-scale features extending across most of Europe. The strongest temperature signals are obtained for the grain type means and the average of all 56 grain price series. This negative relationship also increases in strength moving from annual to decadal timescales while maintaining its significance. An absence of simultaneous significant periodicities in the grain price and climate data demonstrates that the climate-grain price relationships are of an episodic and not a periodic nature.

\subsection{Correlation between solar variability and grain prices}

The sunspot group numbers and the two solar irradiance reconstructions show very different correlation patterns to grain price data (Tables 5 and 6). This is, at least partly, caused by the $\sim 11$-year cycles in the ${ }^{14} \mathrm{C}$ and ${ }^{10} \mathrm{Be}$ solar irradiance reconstructions being incorrect in their timing compared to the actual observed solar cycle as reflected in the sunspot group number record (see Sect. 3.3). We therefore mainly focus here on the correlations between grain prices and the temporally correct sunspot group number observations (although they only extend back to 1610). Significant positive correlations (i.e. higher solar activity $=$ higher prices) are found for the East-central clusters of barley, rye, and wheat prices (Fig. 5). Significant negative correlations (i.e. lower solar activity $=$ higher prices) are observed for the Peripheral clusters for both rye and wheat prices. In addition, significant positive correlations are found with the West-central and Central barley price clusters. These correlations are not affected by lagging the grain prices 1 year relative to the sunspot group number data (Fig. 5).

Considering instrumental data, the strongest correlation between solar variability (sunspot group numbers) and temperature is $r=0.29$ from 1659-1800 for Central England annual mean temperature (and $r=0.21$ for the full period of overlap 1659-2015). The sunspot group numbers are also significantly positively correlated with reconstructed June-August temperature and annual mean temperatures by GR09 and by D10 (the latter only with the $t$ test). Periods with a high sunspot number thus tend to (weakly) correspond to higher temperatures and vice versa. 

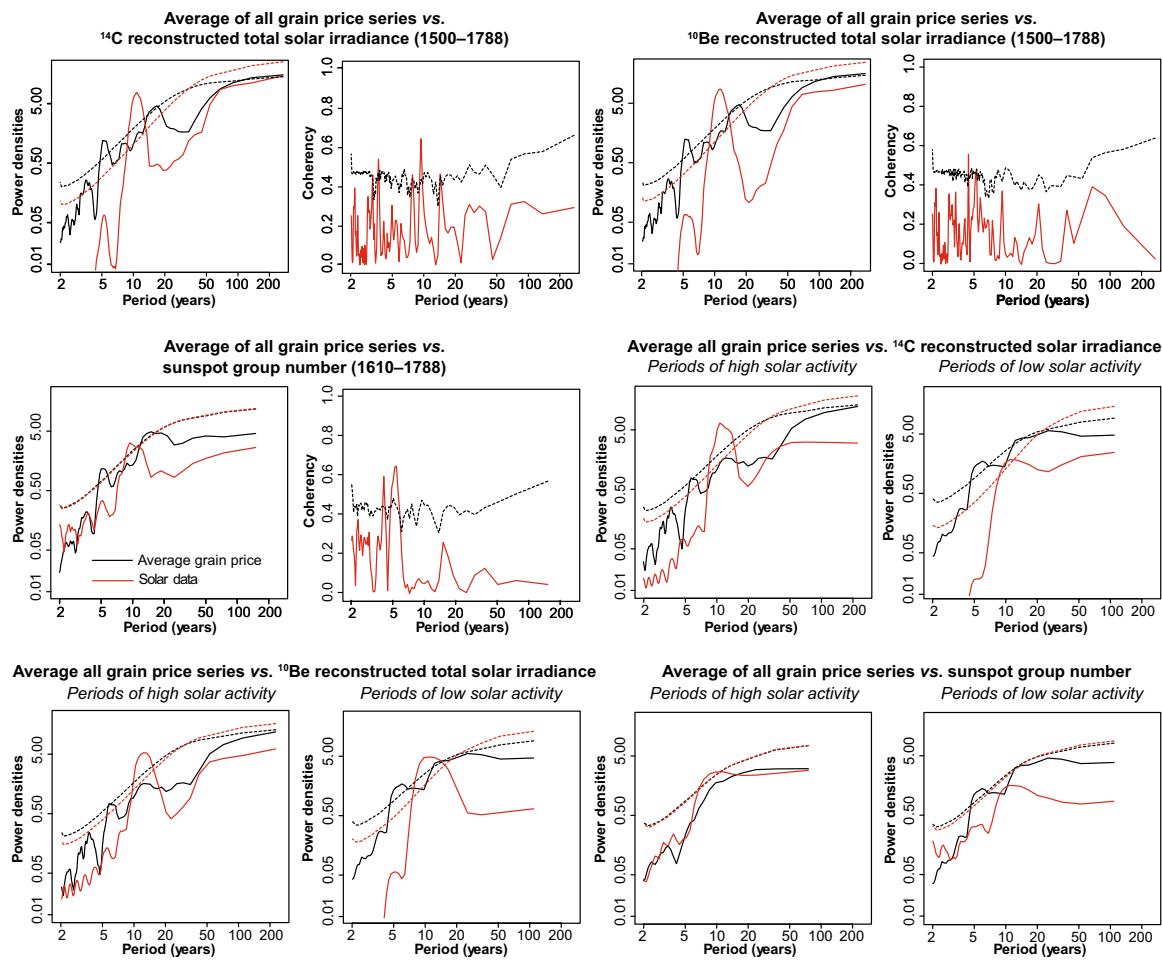

Fig. 9 Spectral power density and coherency analyses between average grain prices and solar variability series. The Thirty Years' War (1618-1648) period is removed. From the middle of the middle row, we show a separate analysis, namely the power spectra for the average grain price series and three solar activity series during periods of high and low solar activity. The grain price average series is divided into intervals corresponding to the solar activity series in the power spectra. Significance calculated as for Fig. 7

\subsubsection{Coherency between grain prices and solar variability}

All three solar variability series contain the well-known $\sim 11$-year sunspot cycle as a highly significant periodicity. They do not contain any other significant periodicities. No corresponding, or even remotely similar, cyclicity is evident in the grain price data (Fig. 9). Nor is the coherency analysis showing any coherency at $\sim 11$-year frequency bands (although the ${ }^{14} \mathrm{C}$ solar irradiance reconstruction contains a significant periodicity of just less than $\sim 10$ years). Coherency is seen at $\sim 5$-year periodicity. This is, as noted in Sect. 4.1.4 above, highly significant in the grain price data. However, even though a weak and insignificant tendency to such periodicity is also found in the spectral analysis of the solar variability series, the $\sim 5$-year coherency cannot be considered robust.

We subdivided both the solar activity estimates and the grain price data into periods of high and low solar activity to assess whether there is significant $\sim 11$-year power in the grain price data during one of these periods, and less so during the 
others, as this would be an indication of a causal link between solar variability and grain prices. ${ }^{11}$ The periodograms of both the solar activity reconstructions for these intervals, and corresponding intervals of the grain price average, are shown in Fig. 9. We observe that there is significant $\sim 11$-year periodicity in solar activity in both time-intervals, with a characteristic shifting of the main, quasi-decadal, intervals with low solar activity which have longer cycles than intervals with high activity-which is a well-known result (e.g. Eddy 1976). Furthermore, we note that there is a significant $\sim 12$-year periodicity in the grain prices, presumably related to similar solar variability, during intervals of low solar activity, but not during intervals of high activity.

\section{Discussion}

\subsection{The grouping of grain price data through cluster analysis}

Grouping the grain price series through hierarchical cluster analysis is a data-driven approach unaffected by a priori presumptions about geographical co-variability patterns among the grain price series. It is entirely the degree of co-variance among the different series that determines the clusters. This data-driven approach used to identify geographic patterns appears more reliable than grouping the data by either historical or present-day political boundaries as regions of high price co-variability are hardly consistent with such boundaries (Chilosi et al. 2013). Hierarchical cluster analysis is similar to principal component analysis, also a data-driven approach, which has successfully been used in economic history by Chilosi et al. (2013) and Studer (2015) to determine regions of wheat price co-variability and, thus, market integration, in early modern Europe.

Hierarchical cluster analysis, like any other method, has its limitations (Christiansen 2007) and may produce spurious patterns if co-variability is generally low. Even if this is not the case, there can still be borderline cases, where the grouping of particular grain price series remains ambiguous. One such case is arguably that the geographically nearby data from Cologne and Frankfurt fall into different clusters (groups) for rye prices. Alternative approaches considering geographically or politically predefined regions would fail to detect such patterns. Furthermore, they would be disadvantageous because changes in grain prices in a region were not necessarily a result of changes in productivity within the same region. Cluster analysis and similar data-driven approaches, on the other hand, group the grain price data with regard to their actual co-variability regardless of whether it is a result of changes in regional productivity or because of changes in trade patterns or trade costs.

The grouping through hierarchical cluster analysis is based on the co-variability of price series for each of the four grain types separately. Some of this co-variability

\footnotetext{
11 The periods covered by the Spörer Minimum (1460-1550) and the Maunder Minimum (1645-1715) are classified as having low solar activity. Periods outside the two solar minima are classified as having high solar activity.
} 
may be partly related to common climatic conditions. Nevertheless, trade patterns appear to affect the cluster grouping much stronger. For example, it is not surprising that the rye prices in Pisa belong to the same 'Peripheral' cluster as Gdansk, or that barley and oats prices in Pisa fall in the same 'Peripheral' clusters as Southern England. These patterns are a result of the import of grain from the Baltic Sea region, particularly since the late sixteenth century (Van Tielhof 2002), as opposed to wheat that was a locally grown crop in Italy, and thus falls into the Italy cluster. Some of these potentially surprising group assignments, particularly in the 'Peripheral' cluster, are clearly related to maritime grain trade (Unger 2011). Grouping these data by predefined categories, e.g. by nation or region, would therefore hide these important relationships. This also means that climatic signals in a particular grain price series are not controlled by local, or regional climate conditions, but may instead contain the climate fingerprints from other regions in Europe. Considering that many price series are controlled by climate variations in other parts of Europe, it is not surprising that the highest climate-grain price relationships are found when averaging the price data at larger spatial scales. Thus, the large-scale common variability will be presented in averaged series. In the case of Pisa, regional comparisons with only Italian climate data would therefore remain incomplete.

Different grain price clusters are influenced by varying long-distance trade partly shaped by geography. The East-central cluster, essentially Central Europe, is located in a landlocked area, albeit with important rivers facilitating water transport, whereas the West-central cluster is closer to the coast. The Central cluster is entirely located in the Upper Rhine Valley. The 'Peripheral' cluster is entirely coastal, and arguably a result of maritime trade with overall lower transport costs (Jacks 2004). Not only the price level, but also the price variations, tended to differ between regions dominated by overland trade and regions dominated by water-way trade (Chilosi et al. 2013).

\subsection{Climate forcing on grain price variations}

We have found stronger, and more significant, negative correlations between temperature and grain prices than hitherto reported. Higher temperatures correspond with lower grain prices, and vice versa, and this relationship becomes stronger with increasing spatial scale_confirming earlier findings by Esper et al. (2017) indicating that correlations increase with spatial domain. Our study is the first to demonstrate this negative temperature-grain price relationship across the diverse environmental settings of entire Europe as well as for the prices of barley, oats, rye, and wheat. Wheat was the price-driving grain in early modern Europe (Chilosi et al. 2013). Thus, an increase or decrease in the price for the other grain types is potentially co-influenced by climate-induced yield variations of wheat.

Even if summer temperature alone explains $\sim 40 \%$ of the decadal-scale average European grain price variations, and about $\sim 16 \%$ of the inter-annual variations, a major portion of the grain price variability remains unexplained by climate conditions. However, multiple regression against several different climate variables in 
addition to summer temperature (e.g. annual mean temperature and precipitation) would likely increase the portion of grain price variability explained by climate (see e.g. Edvinsson et al. 2009; Brunt 2015). Multiple regression analyses, however, come with technical problems in demonstrating statistical significance due to regression inter-correlation and dependence (e.g. interrelationship between annual mean and summer temperatures), and were beyond the scope of the present article.

The grain prices were nonetheless controlled only partly by harvest variations which, in turn, were affected by numerous non-climatic factors such as seed quality, pests, diseases and other factors including armed conflicts, labour force availability, demography, epidemics, and market conditions (see Sect. 5.4). We also show that climate had a temporally varying effect on grain prices. The relationship disappeared entirely during the Thirty Years' War (1618-1648) and, to a lesser extent, following the French Revolution (1789). These changes were likely due to the disintegration of established market forces and regional decoupling of trade (Beveridge 1921; Chilosi et al. 2013; Esper et al. 2017). We presume that periods characterised by other, mostly spatially more restricted, armed conflicts also weakened the climate signal in the grain prices. This is, however, not within the scope of this study as armed conflicts were a recurrent situation in early modern Europe. Finally, we note a tendency towards weaker temperature-grain price relationships throughout the eighteenth century, likely related to a lesser grain price sensitivity to harvest variations and an increased market integration manifested in a decreasing grain price volatility (e.g. Chilosi et al. 2013). Unfortunately, it is difficult to determine the effects of various institutional changes, as opposed to climatic influences, using grain price data alone as the prices might be influenced by production across various regions.

It is entirely plausible that the temperature-grain price relationship was stronger during the coldest phases of the Little Ice Age than during its warmer phases. This could explain a particular strong temperature signal in the grain prices during the period from the late sixteenth to the early seventeenth century, compared to during the eighteenth century, as previously suggested by Pfister and Brázdil (1999). When the growing seasons were shorter, the temperature sensitivity of grain yields might increase in a nonlinear manner. The fact that all of the $10 \%$ coldest summers between 1500-1800 occurred between 1574-1704 directly disproves earlier notions by scholars such as Abel (1974) and Persson (1999) that climate "shocks" on early modern agriculture, and thus on grain prices, can be considered random occurrences. Instead such "shocks", as evident from palaeoclimate reconstructions not available to this earlier generation of scholars, followed clear temporal trends of low-frequency climate variability.

The lack of clear regional differences in the relationship between grain price and temperature and hydroclimate is worth attention. A negative relationship between grain prices and hydroclimate (i.e. drier climate condition $=$ higher prices) could have been expected for several of the regional grain price clusters. However, hydroclimate-grain price relationships showing significant correlations are instead mostly positive (i.e. wetter climate condition $=$ higher prices) —as already indicated by Brückner (1895) for western and central Europe. This positive relationship may appear surprising given the drought sensitivity of agriculture in much of Europe, as far north as central Sweden (Edvinsson et al. 2009), and earlier findings showing 
significantly higher grain prices following exceptionally dry summers (Esper et al. 2017). The weak hydroclimate signal we found in the grain prices is likely related to spatial scale. Compared to temperature, hydroclimate shows a very large spatial heterogeneity in general (Ljungqvist et al. 2016) and during summer in Europe in particular (Büntgen et al. 2010). Drought, or excessive precipitation, will for most years have a more local to sub-regional spatial signature than temperature (Ljungqvist et al. 2019). Hydroclimate effects on crops are usually nonlinear, and may even include tipping points beyond which more precipitation (i.e. severe single events) could lead to reduced harvest. Single extreme precipitation events are not captured in the data we use. Finally, we note the possibility that grain agriculture in the past was less drought sensitive than today. It is not straightforward to transfer modern climate-harvest relations into the past considering the differences in farming practices and seed types (e.g. Michaelowa 2001). Historical grain seed varieties could have different properties, and climatic sensitivity, than those of today but comparatively little is known about this (for an example from Sweden; see Leino 2017).

At longer temporal scales, and larger spatial scales, temperature appears to be the dominating climate factor influencing early modern grain harvests and prices. Brázdil et al. (2019) reported an inconsistent, and statistically insignificant, relationship between drought and seventeenth and eighteenth century grain prices in the Czech Lands, with only a clear signal during certain extreme drought years. In England, dry conditions-except when very severe and prolonged-were normally advantageous for wheat yields (Brunt 2015) and rarely detrimental for barley, rye, and oats yields (Scott et al. 1998; Michaelowa 2001; Pribyl 2017). Considering that wheat was the grain price driver, drought had presumably more modest effects on barley, rye, and oats prices than on their yields.

\subsection{The effect of solar variability on grain prices}

The solar variability signal on the grain prices is weak, and temporally inconsistent, as opposed to the significant and consistent climate signals. This is not surprising considering that solar variability only indirectly affected grain prices through its effects on climate. The rather weak, though significant, solar forcing on climate would further be masked in the grain prices, which only partly depend on climate, and might be distinct during certain periods only. A solar forcing signal in the climate, transferred to the grain prices, would additionally be complicated by, for example, much stronger albeit more short-lived volcanic forcings (Breitenmoser et al. 2012; Esper et al. 2013a, b), and a larger unforced natural variability in the climate system across timescales (Luterbacher et al. 2016; Wang et al. 2017)_ although we found no highly significant associations between large volcanic eruptions and grain prices (not shown). ${ }^{12}$

\footnotetext{
12 We investigated the influence of larger volcanic eruptions, usually inducing sharp summer cooling, on the grain prices, but found the results to be sensitive to the exact selection of volcanic eruptions and the implementation of the various analysis methods.
} 
We conclude that there exist too many overlaying signals in the grain prices to detect distinct solar cycle influences, even if there would be such an underlying control on harvest yields. The influence of solar forcing also appears to show spatial heterogeneity, much like that of precipitation and drought, presumably resulting in an averaging out of any solar signals in grain prices at larger spatial scales. We hypothesise that the weak, and temporally variable, solar-modulated climate influence on grain prices is the reason for previous contradictory findings (Sect. 2.2). This conclusion is in line with the results of Love (2013) who demonstrated that sunspot number-grain price correlations claimed to be significant became insignificant when the independent degrees of freedom were considered. Our finding of a marginally significant power density at $\sim 12$ years in grain price averages for periods of low solar activity, while there is no such sign at periods of high solar activity, might be an example of a temporal unstable (weak) solar-grain price relationship or, alternatively, just a spurious correlation.

\subsection{Grain price and harvest yield relationships}

The strong temperature-grain price relationship reported here for early modern Europe is noteworthy because grain price variability only partly, and indirectly, reflects harvest yield variations that, in turn, also depend on non-climatic factors. The relationship between climate variability, harvests, and grain prices is additionally controlled by demographic pressure, economic conditions and the political and institutional setting (Bauernfeind et al. 2001; Mauelshagen 2010; Krämer 2015). Grain prices are also affected by the organisation of markets, efficiency and cost of transportation, and levels of demand (Bateman 2011, 2015; Chilosi et al. 2013). Domestic prices could, to a considerable extent, be affected by inflationary policies at the same time as international grain prices played a greater role than regional harvest yields (Persson 1999). To further complicate matters, it could take several years for prices in more peripheral regions to adjust to international changes (Edvinsson 2012).

The scarceness of accurate harvest data makes it challenging to quantify the strength of the nonlinear relationships between grain price and harvest variations in early modern Europe over larger spatial scales. Studies of this are also hampered by the fact that only local- to regional-scale harvest estimates are available, whereas grain prices typically reflect larger spatial scales. The correlation between tithe revenues (reflecting yields) and rye prices for the Nuremberg region in southern Germany between 1339 and 1670 has been found to be as low as $r=-0.4$ (i.e. only $16 \%$ of the tithe variance is predictable by price) (Bauernfeind and Woitek 1996). However, during medieval times, with less developed markets, studies for England suggest stronger yield-price relationships (Campbell 2010, 2016; Camenisch 2015; Bekar 2019).

A reasonable presumption is that harvest variations show a stronger climate influence compared to grain price variations, because the former were much less affected by human agency than the latter. However, Camenisch and Rohr (2018) have instead tentatively suggested the relationship between climate variability and grain prices to be stronger than the relationship between climate and harvest yields. The rationale 
for this reasoning is that grain prices represent production over a larger geographical region and are thus less biased by local-scale growth conditions. Partly along the same lines, Edvinsson (2012) suggested that the aggregated grain price level variability can serve as a good indicator of harvest variations in early modern Europe as a whole, whereas grain prices are not good indicators of regional-scale harvest variations in parts of Europe that had a developed market. This could explain why we find the highest temperature-grain price correlations when using the grain price average of all 56 series.

There is an obvious need for further research on harvest-grain price relationships in early modern Europe as well as on the climate signal fingerprint in harvest yields. Some research has been conducted about harvest-grain price relationships for medieval England (Schneider 2014; Campbell 2016; Bekar 2019). Other studies have been conducted for the early modern period and not exclusively for England (Bauernfeind and Woitek 1996; Nielsen 1997; Wrigley 1989). These studies show, at most, moderately strong harvest-price relationships. We envision that future harvest-grain price relationship studies to a large extent employ tithes [a typically $10 \%$ tax levied of the harvest; Kain (1979)] as estimates of harvest size. The challenges are considerable, however, as the extent to which the long-term tithe trends actually represent productivity changes is uncertain and because tithe series are available for some regions only (e.g. Le Roy Ladurie and Goy 1982; Leijonhufvud 2001; Santiago-Caballero 2014). Another source of actual harvest data is manorial harvest yield records (Slicher van Bath 1963). However, relatively few long such records exist, and they reflect local (estate) scale yields, which are not necessarily representative even at a regional scale (Campbell 2016).

\subsection{Climate adaptation of agriculture and the effects of market integration}

The impact of climate variability on grain prices is likely mitigated by different adaptation strategies making grain agriculture more resilient to climate fluctuations (Ljungqvist 2017). A growing body of literature has shown how farming, and society at large, in early modern Europe adopted and adjusted to climatic change and variability [for a review, see Ljungqvist et al. (2021)]. Cultivation at various elevations and sites with different soil properties and climate sensitivities along with a growing diversification of grain crops altered climate resilience. The cultivation of different crops, with different climate response, as well as the entire change of crops to cope with long-term climatic changes were potentially successful adaptation strategies practised at different spatio-temporal scales (Ljungqvist et al. 2021). Both wheat and rye were grown in most regions of Central Europe (Landsteiner 2005), with barley taking the role of rye on the British Isles (Campbell 2016), to reduce the risks of harvest failure of one grain crop. Barley and oats were also cultivated, primarily for beer production and animal feed in Central Europe, that in times of scarcity could be an important human food source (Landsteiner 2005). Even in comparably warm regions, such as Ottoman Bosnia, farmers altered practices and changed to barley, oats and spelt, instead of wheat, during the climax of the Little Ice 
Age (Mrgić 2011). Such adaptation was even applied at the northern edge of grain agriculture, where in present-day Finland autumn-sown rye, which ripens earlier, replaced barley as the main crop during the cold seventeenth century (Huhtamaa and Helama 2017b). Finnish farmers also responded to cold climatic periods by increasing slash-and-burn cultivation in substitution of permanent fields (Huhtamaa and Helama 2017a). Similarly transitions from cold-sensitive wine grapes to coldtolerating barley for beer production are found in parts of Central Europe during the climax of the Little Ice Age (Landsteiner 1999).

The storage and trade of seed corn were important to reduce the impacts of adverse climate conditions on grain production and prices (Krämer 2015). The lack of grain seeds after years of unfavourable climatic conditions constrained harvest yields for one to two more years in regions with low market integration (Hoskins 1964, 1968; Appleby 1979; Bekar 2019). This problem lessened in many European regions throughout the early modern period, although it persisted in marginal fringe areas with a low market integration. However, storage facilities such as public grain magazines could provide a safer access to seed corn, as well as dampen the price shocks of grain, after poor harvests (Alfani and Ó Gráda 2017). Grain magazines became increasingly common during the eighteenth century (Collet 2010) even in marginal regions such as Norway (Hansen 2015). The access to, and price of, grain and other commodities were negatively affected during cold periods, when yields decreased in larger regions and over longer periods, also by frozen water bodies that hampered shipping and land transport (Krämer 2015). This was such a major problem for communication and commerce that labour-intensive ice removal was undertaken already in the fourteenth century on waterways in the Low Countries (De Kraker 2017).

Besides climate variability, the development of agricultural technology and labour force was of substantial importance to early modern grain harvest and prices. At a continental scale, this is expressed by the similar grain yield ratios (Slicher van Bath 1963) between western and eastern Europe prior to $c$. 1570, a similar decrease during the climax of the Little Ice Age (c. 1570-1710) in both regions of Europe, but very different recovery patterns. During the eighteenth century, sociopolitical and technological differences caused grain yield ratios in western Europe to increase much above their pre-1570 level, whereas this did not occur in eastern Europe (Pei et al. 2016). Similar differences attributable to a range of institutional and technological factors supported a higher productivity, and lower climate sensitivity, of English compared to French grain agriculture during the eighteenth century (Michaelowa 2001; Brunt 2015). Mixed farming methods, improvement of the soil quality, along with stronger market incentives also increased English yields earlier than at most other places in Europe (Tello et al. 2017). To assess the decreasing climate sensitivity of grain agriculture, due to institutional and technological advances, actual harvest yield data rather than price data need to be considered in future studies. Moreover, it would be practically impossible to statistically assess influences of agricultural adaptation to climatic change in our grain price data as the time periods considered then would be too short to reach statistical significance given the relatively low climate-price correlations (see, however, Esper et al. 2017). 
Socio-political and technological factors explain most of the decreasing grain price volatility, and increasing price convergence, through an improved market integration towards the end of the early modern period. However, it is possible that climatic change could have played a small part as well. Periods with extremely cold years, causing more frequent adverse growth conditions in large portions of Europe, would supposedly have contributed to a higher grain price volatility. Furthermore, locations towards the north, and at higher elevations, would be the regions most affected by periods with more frequent exceptionally cold years (or growing seasons). Consequently, the grain harvests would be affected to various extents in different parts of Europe, which theoretically could contribute to a decreased price convergence over the continent. Several scholars, most notably Bateman (2011, 2015), have found about as high a degree of European grain market integration in the first half of the sixteenth century as in the second half of the eighteenth century, but a much reduced grain market integration during much of the intervening period. This period of market decoupling - the late sixteenth century and the seventeenth century-coincides with the climax of the Little Ice Age. However, correlation does not equate causation, and we support the consensus view that socio-political factors, mainly frequent and large-scale warfare, explain most of the market contraction. We believe the question of a possible climatic contribution to this grain market decoupling can be tested empirically in future research by analysing both grain yield data and grain price data together with palaeoclimate data and early meteorological measurements.

\subsection{Comparison with previous findings}

The existence of a climate influence on grain prices in early modern Europe is well established for inter-annual timescales, but has been a matter of debate for longer timescales (see Sect. 2.1). However, Esper et al. (2017) demonstrated the presence of a significant temperature effect on grain prices also at multi-decadal to centennial timescales. We have found an even stronger, and more significant, temperature-grain price relationship than Esper et al. (2017) by analysing 56 instead of 19 grain price series and employing an updated June-August temperature reconstruction and, in addition, two annual mean temperature reconstructions. Importantly, we find 10-year low-pass filtered data to show stronger correlations and still, despite the reduced degrees of freedom, to be statistically significant, whereas Esper et al. (2017) reported similar correlations to be statistically insignificant. These differences could partly be related to different smoothing techniques, as Esper et al. (2017) use spline smoothing instead of box-car smoothing (Appendix B), though the much increased European grain price network employed here was likely needed to reach significance.

Although temperature has been found to be the most important climate variable for early modern grain prices, numerous studies have also pointed to the significance of drought or excessive precipitation (Sect. 2.1). We only found week, inconsistent, and regionally varying effects of hydroclimate on the grain prices. This is partly at odds with Esper et al. (2017) who detected a negative high-frequency summer 
drought-grain price relationship. These conflicting findings are presumably related to the fact that we did not study, in particular, high-frequency climate-grain price relationships. The importance of temperature, relative to drought and precipitation, for grain yields and prices clearly increases towards lower frequencies as well as with increasing spatial scale.

We have noted a highly significant $\sim 5$-year and a weakly significant $\sim 16$-year periodicity in the grain price data (Fig. 7). The $\sim 16$-year periodicity corresponds to the original findings by Beveridge (1921) of a 15.3-year cyclicity of early modern grain prices in western and central Europe. More recently, Scott et al. (1998) reported for England a 5-6-year and a broader 13-16-year oscillation in barley, oats, and wheat prices. Beveridge (1922) linked his 15.3-year cyclicity to periodicities in precipitation, while Scott et al. (1998) emphasised the importance of temperature as well as precipitation for their $\sim 13-16$-year oscillation but found their $\sim 5-6$-year oscillation unrelated to climate. Conversely, we have been unable to detect any significant coherency between grain prices and climate for either the $\sim 5$-year or the $\sim 16$-year periodicities. This absence of coherent periodicities between grain prices and climate (or solar) variability disproves earlier presumptions of a cyclicity. It demonstrates the presence of an episodic instead of a periodic (cyclic) relationship.

\section{Conclusions}

The importance of direct climate effects, as well as indirect influences of solar variability, for grain price variability in early modern Europe (c. 1500-1800) has been contested issues, with previous scholarship showing partly conflicting results. We have systematically revisited these questions, within a framework of rigid statistical testing, by employing an unprecedentedly large network of 56 grain price series of multi-centennial length, and benefiting from recent advances in palaeoclimatology and solar physics. A highly significant negative grain price-temperature relationship (i.e. colder $=$ high prices and vice versa) is apparent across most of Europe, valid for barley, oats, rye, and wheat. Over the 1500-1788 period, excluding the Thirty Years' War (1618-1648), the correlation is as strong as $r=-0.41$ between previous year June-August temperature and the average of all grain price series. This negative correlation increases to $r=-0.63$ at decadal timescales. Conversely, we found only weak and spatially inconsistent relationships between grain prices and hydroclimate (precipitation and drought). No robust evidence could be detected for the existence of an effect of solar forcing on early modern grain prices.

Considering that summer temperature variability alone, at decadal timescales, explained as much as $40 \%$ of the variance in average European grain prices, climate must be considered an important historical agent given that grain prices played such a decisive role in the early modern European economy. Grain price variability was a major driver behind changes in real wage levels and the average standard of living, and periods of high grain prices were frequently triggering 
malnutrition, crisis, and civil unrest. Our findings therefore demonstrate that temperature variability was an important factor influencing grain price variability, on inter-annual to multi-decadal timescales, across Europe supporting the argument that climate variability played a significant role in human history.

\section{Appendix 1: A brief overview of solar variability and solar-climate links}

Sunspots are areas of lower temperature in the photosphere, or 'surface', of the Sun related to magnetic activity in and around the Sun. The spots are relatively short-lived, surviving at most a couple of months, and are observed to appear in differing numbers on the Sun with an approximately 11-year cycle. At times, between cycles, they disappear completely. At other times, near cycle maxima, they can be so large that they can be seen with the naked eye. Using telescopic observations, their numbers have been registered since the early 1600s (Stephenson 1990; SILSO World Data Center, 1994-2014; Svalgaard and Schatten 2016; Muñoz-Jaramillo and Vaquero 2019). It appears clear that there were fewer sunspots during the so-called Maunder Minimum ( 1645-1715), with possibly sunspot cycles even missing at times (Eddy 1976). The $\sim 11$-year sunspot cycle is the visible expression of an underlying $\sim 22$-year magnetic cycle in the upper layers of the Sun. Superimposed on the $\sim 11$-year cycles are centennial and longer cycles of activity (Peristykh and Damon 2003; Gray et al. 2010).

Direct influence of the variations in solar activity on Earth's atmosphere and climate system has been investigated for a long time (e.g. Herman and Goldberg 1978; Hoyt and Schatten 1997; Lilensten et al. 2015). Since the 1990s detailed physics-based (i.e. not statistics-based) investigations have considered how solar irradiance variability could drive certain variabilities found in Earth's atmosphere [see e.g. Haigh 1996)]. The solar irradiance is not constant with time, but is correlated with the $\sim 11$-year sunspot cycle. In fact, the irradiance is slightly higher when there are more spots, since tiny but very bright 'faculae' on the solar photosphere accompanying the darker spots compensate for the loss of light in the spots. Visible light varies in time with the solar cycle to an extent of some tenths of a percent, while ultraviolet light varies more. Investigations by e.g. Haigh (2003) have focused on how absorption of ultraviolet light in the upper atmosphere on Earth might influence dynamics of the atmospheric system. Other investigators, e.g. Svensmark et al. (2009), have considered the variable influence of the cosmic ray flux on cloud nucleation processes in lower layers of the atmosphere. While cosmic rays originate outside the solar system their flux at Earth is a function of the level of the solar activity, and hence the Sun has an influence on the flux of ionising particle radiation in the atmosphere. The cosmic ray flux generates radio-nucleides such as ${ }^{14} \mathrm{C}$ and ${ }^{10} \mathrm{Be}$ in the atmosphere from spallation of nitrogen (Poluianov et al. 2016) preserved in tree-ring data and icecore data, respectively. Such datable records can thus be used as solar activity records back in time (Beer et al. 1990; Steinhilber et al. 2009; Jungclaus et al. 2017). 
Although there is certainly an influence of solar activity on the climate system, the effect is generally estimated to have been rather small on the inter-annual to multi-decadal timescales of interest here. On longer timescales there are cycles in the radio-nucleide abundances that become evident when millennial-length records of estimated solar activity are analysed. Some readily apparently coincidental fluctuations of these long cycles and climate variations have fostered work on whether there is a solar influence on climate with a larger signal on longer timescales (Siscoe 1978; Breitenmoser et al. 2012; Taricco et al. 2015). Various authors have also reported significant correlations between solar activity and precipitation. A recent example is Laurenz et al. (2019), demonstrating significant correlations between precipitation and solar activity for many months of the year over much of Europe 1901-2015.

\section{Appendix 2: Effective degrees of freedom for box-car and spline-filtered data}

In order to test the degree to which the correlations we observe are derived from lower frequencies, we apply two forms of 10-year low-pass filters to all the data and recalculate the correlation matrices. The two filters are the box-car method giving one value per decade by the calculation of 10-year non-overlapping block averages, and the spline-method that delivers annual, but smoothed, values. The traditional parametric $t$ test for correlation significance is based on letting the degrees of freedom be equal (or almost equal: $n-2$ ) to the number of data points and is too generous in cases where serial correlation in the series are present and thus lower the effective degrees of freedom. You can, in this case, either turn to such methods as Monte Carlo-based phase scrambling surrogate data methods, or employ an older and simpler-but also effective-method based on the standard parametric methodology, but replacing the degrees of freedom in the formula used for the test with the effective degrees of freedom which takes serial correlation into account.

We note the sparseness of positive grain price cross-correlations when using the method of Bartlett (1935) vs. phase scrambling methods. This could be due to some of the correlations between the grain price series being due to periodicities below the 10-year period-these are taken out by the box-car filtering and if they were dominant then the corresponding series correlations become insignificant upon box-car filtering. Furthermore, we note the negative correlations between grain prices and temperature (notably June-August temperature) using annually resolved data, and stronger anti-correlation using 10-year low-pass filtered data. This could be interpreted as an effect of the filtering-removal of some shorter periods may have mitigated noise, allowing a stronger correlation to come through. It can also be interpreted as that at least some of these correlations are random events-only a few are able to come above the cut-off set by the significance limit, and the significance level is higher for the box-car filtered series as there are fewer degrees of freedom than in the annually resolved case; hence, chance correlations will inevitably seem larger in the box-car case as compared to 
the annual data case. Series cross-correlations make the analysis of this suggestion intractable.

Finally, we note that the method of Bartlett (1935) applied on the 10-year boxcar filtered data gives very similar results to those of the phase scrambling method. The standard parametric method applied to box-car-filtering is also not too different. However, in the spline-filtered case large differences between the methods are seen. We see that the method of Bartlett (1935) on spline-filtered data is extremely conservative, ruling out most cross-correlations except between grain price series.

Table 3 The auto-regressive nature of the 10-year low-pass box-car and spline filtered timeseries analysed in this study

\begin{tabular}{|c|c|c|}
\hline Time-series & Box-car & Spline \\
\hline Barley East-central & 0 & $1,2,3$ \\
\hline Barley Peripheral & 1 & 1,2 \\
\hline Barley West-central & 1 & 1,2 \\
\hline Barley Central & 1 & 1,2 \\
\hline Barley mean & 1 & 1,2 \\
\hline Oats Peripheral & 1 & 1,2 \\
\hline Oats West-central & 0 & $1,2,3,4$ \\
\hline Oats Central & 0 & $1,2,3,4$ \\
\hline Oats mean & 1 & $1,2,4,5$ \\
\hline Rye East-central & 1,4 & $1,2,3$ \\
\hline Rye Central & 0 & $1,2,3,4$ \\
\hline Rye West-central & 0 & $1,2,4,5$ \\
\hline Rye Peripheral & 1 & $1,2,4$ \\
\hline Rye mean & 1,3 & $1,2,3,4$ \\
\hline Wheat Spain & 1,8 & $1,2,4$ \\
\hline Wheat Italy & 1 & $1,2,4$ \\
\hline Wheat West-central & 1 & $1,2,3,4$ \\
\hline Wheat East-central & 4 & 1,2 \\
\hline Wheat Peripheral & 1 & $1,2,4,5$ \\
\hline Wheat mean & 1,3 & $1,2,3,4,5$ \\
\hline Grain price average & 1,3 & $1,2,4$ \\
\hline Europe JJA temperature & 1 & $1,2,3$ \\
\hline C. Eur. ann. temp. (D10) & 0 & 1,2 \\
\hline C. Eur. ann. temp. (GR09) & 0 & $1,2,3,5, \ldots$ \\
\hline scPDSI Mediterranean & 0 & 1,2 \\
\hline scPDSI East-central & 0 & $1,2,3$ \\
\hline scPDSI West-central & 0 & $1,2,3,4$ \\
\hline Solar irradiance ${ }^{14} \mathrm{C}$ & 1 & $1,2,3,4,5$ \\
\hline Solar irradiance ${ }^{10} \mathrm{Be}$ & 1 & $1,2,3,4,5,6$ \\
\hline Sunspot group no. & 1 & $1,2,4,5$ \\
\hline
\end{tabular}

Column 1 gives the name of the series, column 2 gives the lag at which a significant partial auto-correlation coefficient (PACF) is found for the box-car series, and column 3 gives the same but for the spline filtered series 
We think these large differences in the last point above are due to the very different nature of time-series filtered by the box-car and the spline filtering methods.

\section{Appendix 3: The auto-regressive (AR) structure of box-car and spline-filtered time-series}

We tested for the effects of box-car and spline 10-year low-pass filtering of the timeseries. The partial auto-correlation function is calculated for many lags and the significant partial auto-correlation coefficient (PACF) were found (Table 3). We see that all spline-filtered series are at least AR1 processes but very often also of higher order and complex structure, while the box-car filtered series can be simple, of order 0 (i.e. they are not auto-correlated). The majority of the box-car filtered series are AR1 and nothing more; a small number can be of higher order such as 3 and 4 and 8 -but never 2 .

From this we conclude that box-car filtering allows significance testing with standard parametric methods for about one-third of the series, while some sort of attention to the AR1-nature has to be made for about two-thirds of the series. As the AR-structure often is no more complex than AR1 we can apply such simple methods as Bartlett (1935) using the 'effective degrees of freedom' instead of the standard 'all points' method. However, for the spline filtered series it is obviously not valid to use such simple methods given the more complex time-series structure. Surrogate data methods are instead called for or, alternatively, auto-regressive moving average (ARMA) modelling.

We expect the simple methods_-applied to spline filtered data-to yield results that are too optimistic, or invalid, in the significance testing. We have also performed the same analysis on annual data (not shown), with results similar to the spline filtering case - that is, the time-series structure is 'complex', but not as 'exotic' as the spline filtering case, and we remind the reader that the Bartlett (1935) method really only should be expected to work well in the AR0 and AR1 cases, while the phase scrambling method has a high chance to work in general. The standard parametric test is only applicable to the AR0 cases.

\section{Appendix 4: Implementation of spectral analysis methods}

Spectral analyses of time-series can identify whether similar periodicities exist in two time-series even if these periodicities is not in-phase with each other. In order to test the statistical significance of detected periodicities surrogate-based significance testing methods can be employed. Suitable surrogate-based significance testing can be based on the white-noise surrogate method or on a method that generates surrogate data with the same auto-correlation at lag 1 (AR1) as the original data. The white noise method will tend to be too optimistic while the AR1-based method is more conservative and does not give as high a false positive rate.

Continuous time-series are well analysed with spectral methods based on the fast Fourier transform. We, however, are operating with time-series that may contain 
A

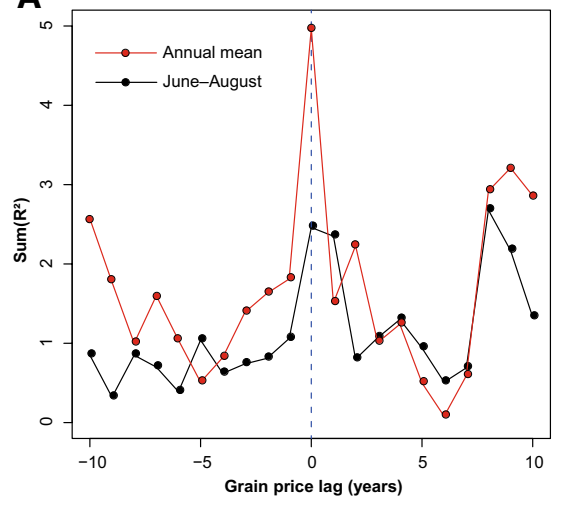

B

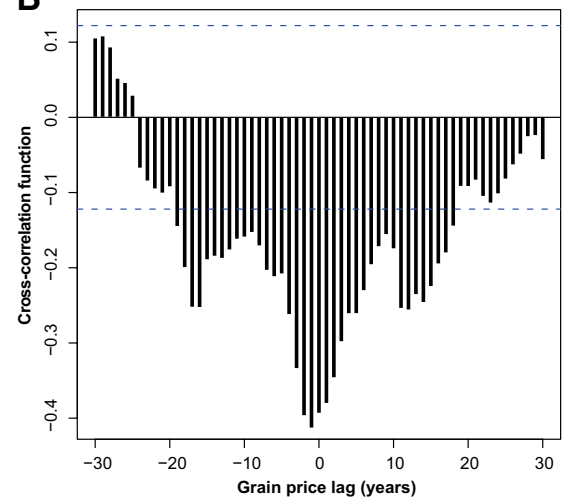

Fig. 10 Effect on the cross-correlation function when letting grain prices lag climate (in years). a Effect of time-shifts on the correlation between the grain price clusters and the five instrumental temperature and five instrumental precipitation series for annual mean and June-August values, respectively. An overall index is displayed consisting of the sum of all significant squared correlations estimated using the phase-scrambling-based significance test. b Correlation coefficients when letting the average of all grain price series lag reconstructed European average June-August temperature. The dashed blue lines indicate the confidence interval calculated from the null-hypothesis that the series are white noise-like (which they are not; thus, the levels are optimistic)

longer gaps-indeed, we want to exclude the period corresponding to the Thirty Years' War (1618-1648) in order to exclude e.g. grain price data for a period when ordinary market forces were, to a large extent, disabled and prices no longer reflected the harvest size influence of external factors such as climate. We also want to perform an analysis of spectra during times of high and low solar activity; this likewise generates gaps in the series. When time-series have gaps, one should take steps to avoid - or at least understand - the effects due to so-called 'spectral aliasing'. We have extensively tested (not shown) whether the imposition of the data gap due to the Thirty Years' War (1618-1648) generates spectral artefacts and found that this was not the case. On that basis we use everywhere in this study spectral methods assuming continuous data.

\section{Appendix 5: Effect of time shifts on series correlations}

The question arose whether the correlations seen between grain price data and various climate and solar variability series might be influenced by lagging the grain price series in relation to the latter series before correlating them. Such experiments could test various 'memory effects' in the agricultural and grain trade realm, where crops 1 year may affect crop yield the subsequent year(s), as well as lagged responses between harvest yields and grain prices. We considered the correlations found between grain price data and instrumental temperature and precipitation series (both considering the June-August values and the annual mean values for the instrumental variables). All shifts from -10 to +10 years were considered. We expressed 


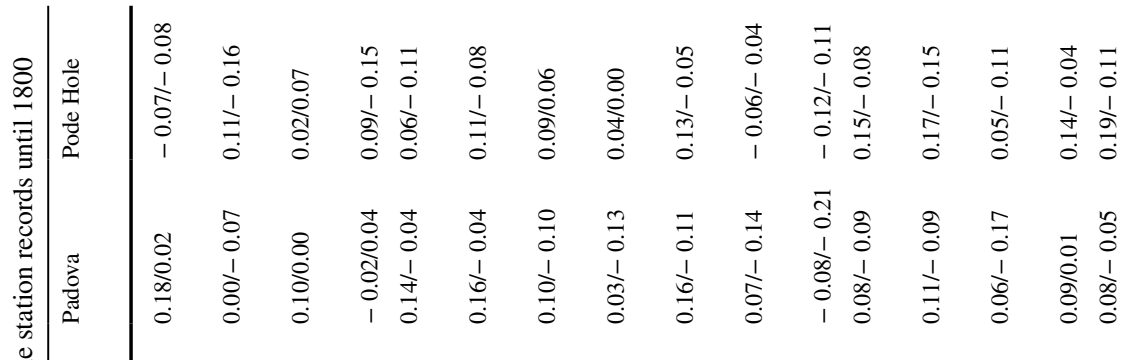

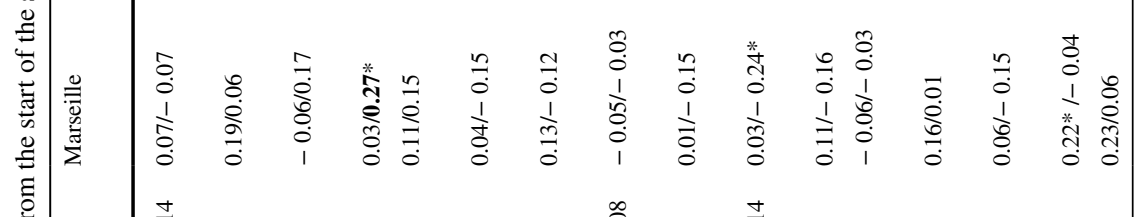

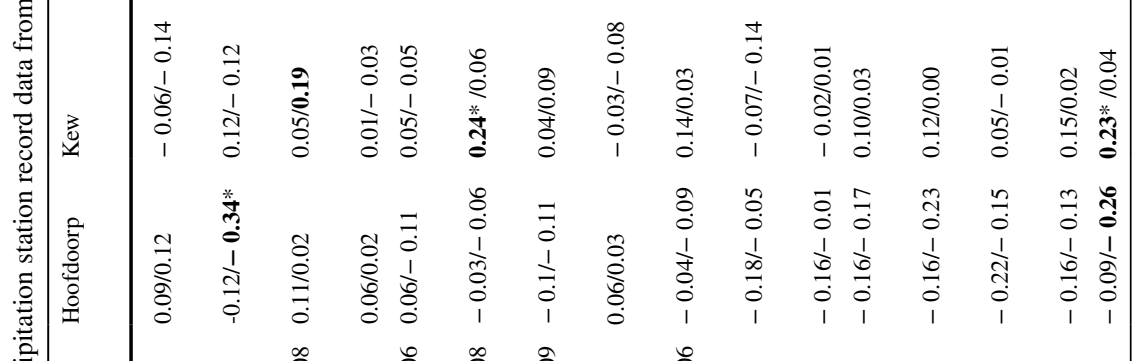

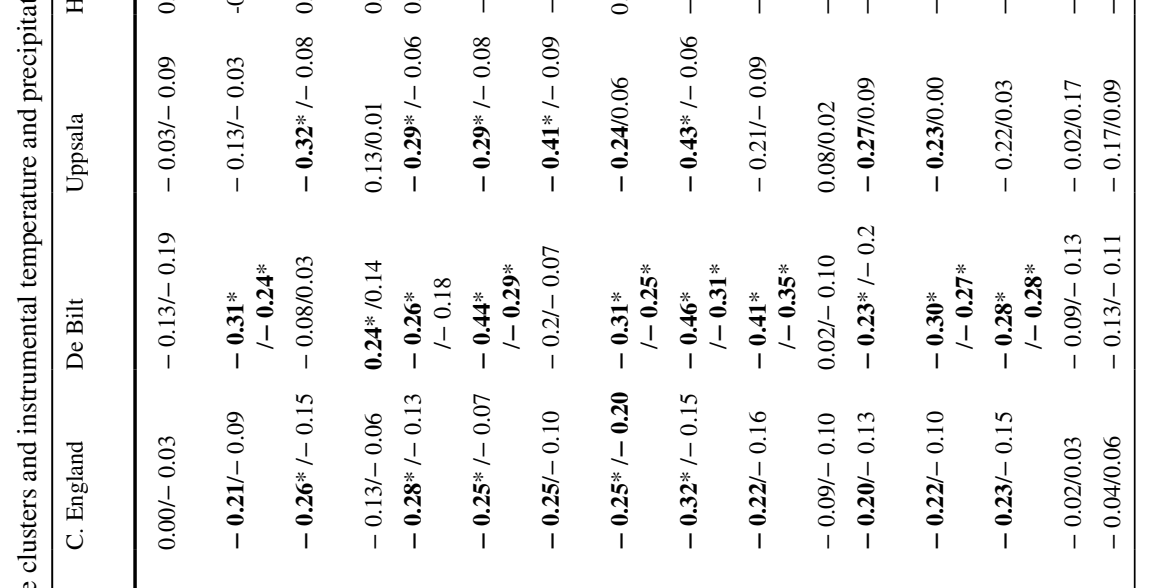

:.

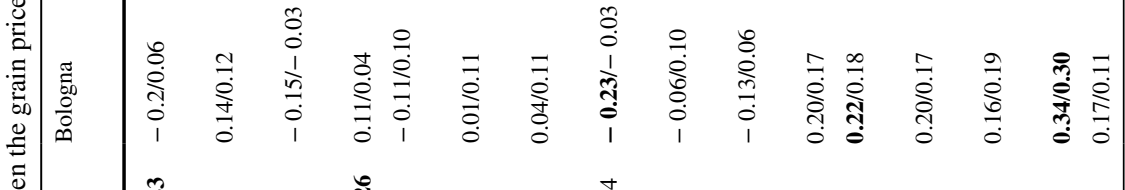

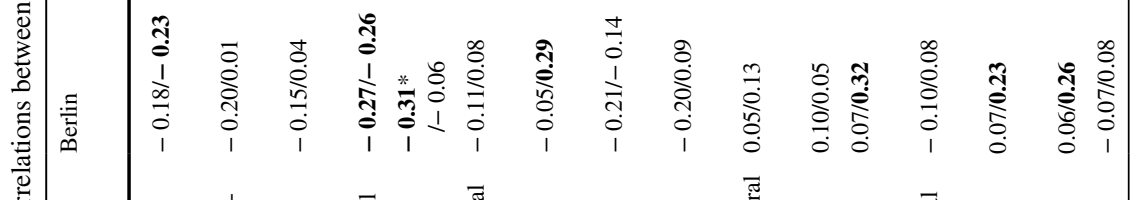

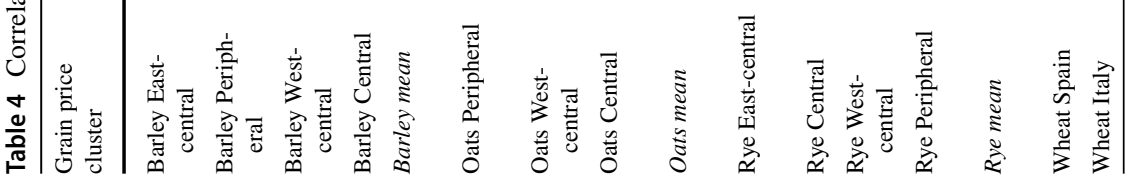




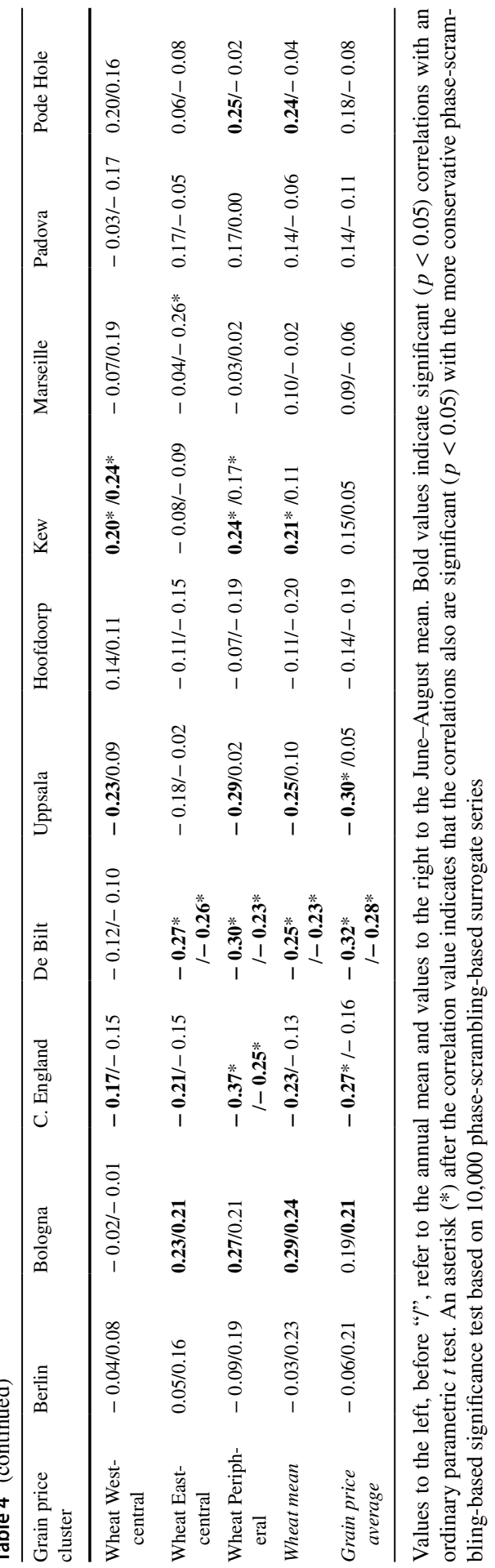




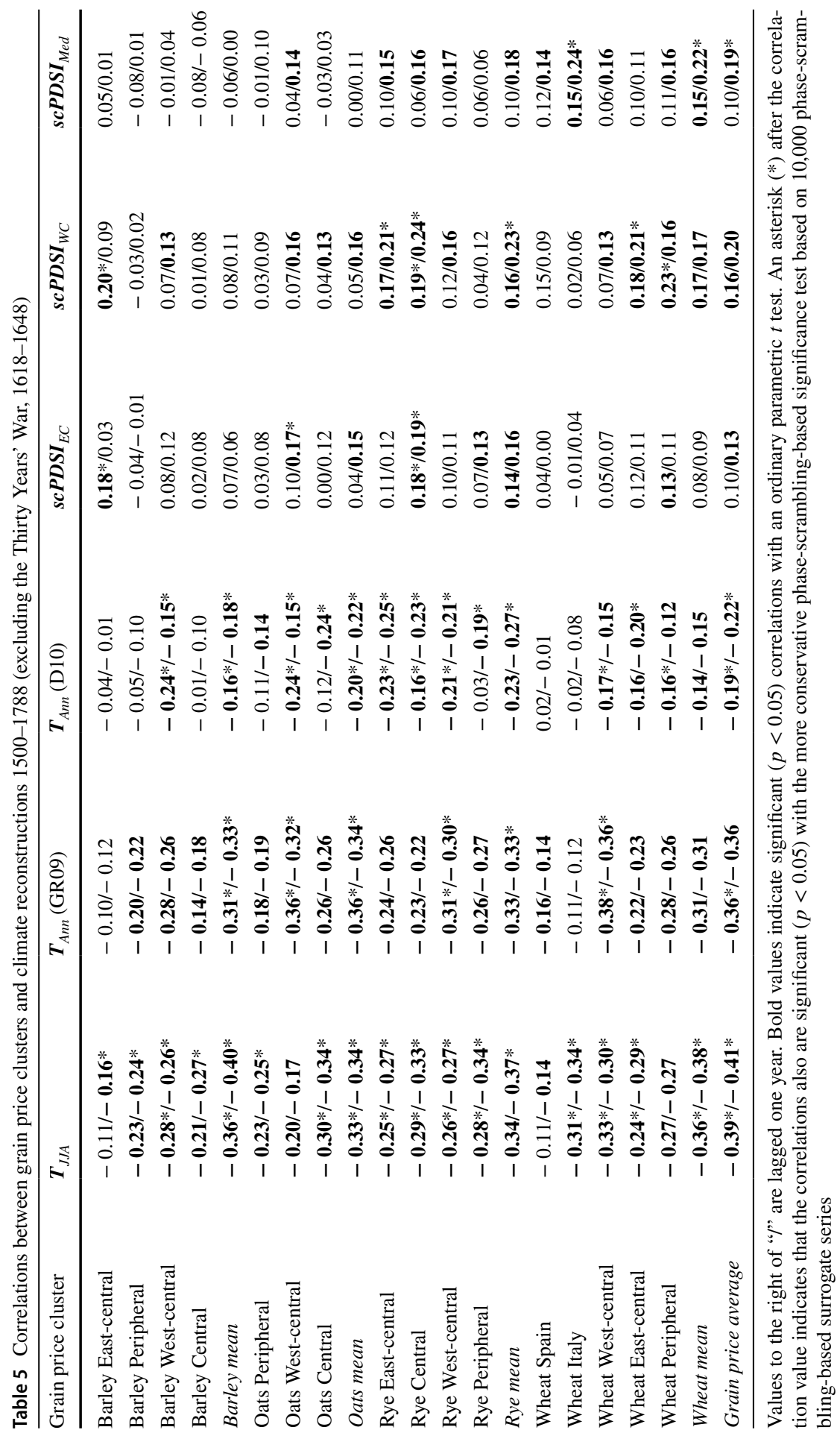




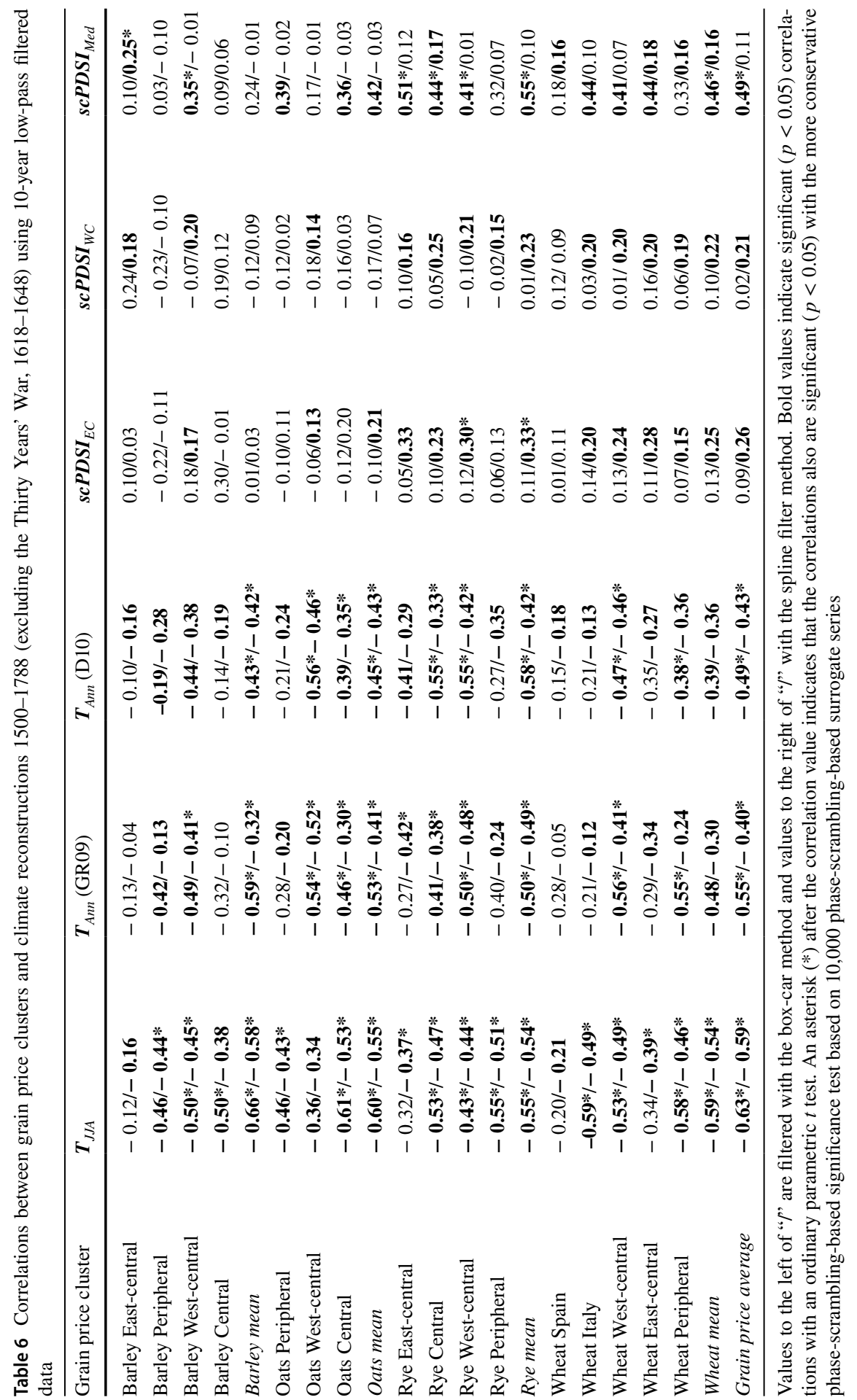


Table 7 Pearson correlation coefficients between grain price clusters and solar variability estimates over the period 1500-1788 (excluding the Thirty Years' War, 1618-1648)

\begin{tabular}{|c|c|c|c|}
\hline Grain price cluster & TSI ${ }^{14} \mathrm{C}$ & $\mathrm{TSI}{ }^{10} \mathrm{BE}$ & Sunspot group no. \\
\hline Barley East-central & 0.12 & -0.01 & 0.20 \\
\hline Barley Peripheral & 0.13 & -0.06 & -0.06 \\
\hline Barley West-central & 0.12 & 0.12 & -0.19 \\
\hline Barley Central & -0.06 & -0.05 & -0.23 \\
\hline Barley mean & $0.20^{*}$ & 0.02 & -0.06 \\
\hline Oats Peripheral & $0.30 *$ & -0.05 & 0.07 \\
\hline Oats West-central & $0.16 *$ & 0.12 & -0.11 \\
\hline Oats Central & 0.17 & 0.12 & -0.01 \\
\hline Oats mean & $0.29 *$ & 0.07 & -0.01 \\
\hline Rye East-central & $0.33 *$ & 0.25 & 0.24 \\
\hline Rye Central & 0.17 & 0.09 & 0.05 \\
\hline Rye West-central & 0.18 & 0.11 & -0.02 \\
\hline Rye Peripheral & 0.08 & -0.13 & -0.21 \\
\hline Rye mean & $0.26^{*}$ & 0.14 & 0.07 \\
\hline Wheat Spain & 0.12 & -0.15 & -0.04 \\
\hline Wheat Italy & 0.23 & -0.03 & 0.01 \\
\hline Wheat West-central & 0.13 & 0.06 & -0.12 \\
\hline Wheat East-central & $0.22 *$ & 0.13 & 0.22 \\
\hline Wheat Peripheral & 0.00 & -0.09 & -0.23 \\
\hline Wheat mean & 0.20 & -0.02 & -0.04 \\
\hline Grain price average & $0.25 *$ & 0.04 & -0.01 \\
\hline
\end{tabular}

Values in bold indicate significant $(p<0.05)$ correlations with an ordinary parametric $t$ test. An asterisk (*) after the correlation value indicates that the correlations also are significant $(p<0.05)$ with the more conservative phase-scrambling-based significance test. Abbreviations as follows: TSI ${ }^{14} \mathrm{C}=$ Carbon- 14 reconstructed total solar irradiance; TSI ${ }^{10} \mathrm{BE}=$ Beryllium-10 reconstructed total solar irradiance

the overall level of correlation between the series as the sum of squared correlations $\left(\sum R^{2}\right)$ between all possible pairs of series (one grain price and one instrumental series). We included only correlations that tested significant at the $p=0.05$ level.

At lags of 0 and +1 years we have a peak in the sum of $R^{2}$, for annual values-see red curve in Fig. 10-which is encouraging and is due to temperature and precipitation series generally contributing large negative and positive correlations, respectively, for all series, which builds a large $\sum R^{2}$. However, we also have a strong peak at a shift of +8 years which is due to just the Bologna and Berlin temperature series having strong correlations and anti-correlations with the grain price series at that lag. Summing the $R^{2}$ over the set of series gives little contributions from the other series since their correlations are reduced everywhere by the shifts imposed, while Bologna and Berlin have large $R^{2}$ contributions. It should be noted that the Bologna and Berlin temperature series have opposite sign correlations with grain prices at lag +8 - which is not the case at lags 0 and +1 years. We therefore think that the general auto-correlative nature of these time-series causes a random excursion in $R^{2}$ for 
lags near +8 years unrelated to any physical links. The analysis is based on generating statistics incorporating all series, rather than picking out the 'best' results.

If we use the European average June-August temperature reconstruction, showing the highest correlation to grain price data, and use the grain price average of all 56 series and correlate at a range of lags, we get the more inspiring result shown in the black curve of Fig. 10. A large and significant correlation is found near 0 lag, along with generally significant correlations anywhere between -20 and +18 years. Of course, being selected for having a 'nice' result makes the significance test difficultshown are significance levels from the simple parametric test (Tables 4, 5, 6, 7).

Acknowledgements F.C.L. and A.S. were supported by the Swedish Research Council (Vetenskapsrådet, Grant No. 2018-01272), P.T. by the NordForsk project eSACP (Grant No. 74456), B.C. by the NordForsk-funded Nordic Centre of Excellence project Arctic Climate Predictions: Pathways to Resilient, Sustainable Societies (ARCPATH) (Grant No. 76654), C.H. by the German Science Foundation (DFG, Grant No. HA 8048/1-1), and J.E. by the German Science Foundation (DFG, grant no. ES 161/9-1) and the European Research Council (ERC-2019-AdG Grant No. 882727). F.C.L. conducted the work with this article as a Pro Futura Scientia XIII Fellow funded by the Swedish Collegium for Advanced Study through Riksbankens Jubileumsfond. We express our appreciation to Dario Camuffo for the Bologna temperature observations, to Philip D. Jones and Gerard van der Schrier for assistance with obtaining early instrumental climate station records, to Paul J. Krusic and Björn Lundquist for help with preparing the historical grain price data files, and to Qiang $\mathrm{Li}$ for help with reformatting ${ }^{14} \mathrm{C}$ and ${ }^{10} \mathrm{Be}$ solar forcing time-series. The authors thank the editor and two anonymous reviewers whose useful comments helped improve this article.

Funding Open access funding provided by Stockholm University.

Open Access This article is licensed under a Creative Commons Attribution 4.0 International License, which permits use, sharing, adaptation, distribution and reproduction in any medium or format, as long as you give appropriate credit to the original author(s) and the source, provide a link to the Creative Commons licence, and indicate if changes were made. The images or other third party material in this article are included in the article's Creative Commons licence, unless indicated otherwise in a credit line to the material. If material is not included in the article's Creative Commons licence and your intended use is not permitted by statutory regulation or exceeds the permitted use, you will need to obtain permission directly from the copyright holder. To view a copy of this licence, visit http://creativecommons.org/licen ses/by/4.0/.

\section{References}

Abel W (1974) Massenarmut und Hungerkrisen im vorindustriellen Europa. Verlag Paul Harvey, Hamburg

Alfani G, Ó Gráda C (eds) (2017) Famine in European history. Cambridge University Press, Cambridge

Allen RC (2000) Economic structure and agricultural productivity in Europe, 1300-1800. Eur Rev Econ Hist 4:1-25

Allen RC, Unger RW (2019) The Allen-Unger global commodity prices database. Res Data J Hum Soc Sci 4:81-90

Appleby AB (1979) Grain prices and subsistence crises in England and France, 1590-1740. J Econ Hist 39:865-887

Bartlett MS (1935) Some aspects of the time-correlation problem in regard to tests of significance. J R Stat Soc 98:536-543

Basini GL (1974) Sul mercato di Modena tra Cinque e Seicento: prezzi e salari. A. Giuffrè, Milan

Bateman VN (2011) The evolution of markets in early modern Europe, 1350-1800: a study of wheat prices. Econ Hist Rev 64:447-471

Bateman VN (2015) Markets and growth in early modern Europe. Routledge, London 
Bauernfeind W, Woitek U (1996) Agrarian cycles in Germany 1339-1670: a spectral analysis of grain prices and output in Nuremberg. Explor Econ Hist 33:459-478

Bauernfeind W, Woitek U (1999) The influence of climatic change on price fluctuations in Germany during the 16th century price revolution. Clim Change 43:303-321

Bauernfeind W, Reutter M, Woitek U (2001) Rational investment behaviour and seasonality in early modern grain prices. Eur Rev Econ Hist 5:281-298

Beer J, Blinov A, Bonani G, Finkel RC, Hofmann HJ, Lehmann B, Oeschger H, Sigg A, Schwander J, Staffelbach T, Stauffer B, Suter M, Wötfli W (1990) Use of ${ }^{10} \mathrm{Be}$ in polar ice to trace the 11-year cycle of solar activity. Nature 347:164-166

Bekar CT (2019) The persistence of harvest shocks in medieval England. J Econ Hist 79:954-988

Beveridge WH (1921) Weather and harvest cycles. Econ J 31:429-452

Beveridge WH (1922) Wheat prices and rainfall in western Europe. J R Stat Soc 85:412-475

Brázdil R, Durd'áková M (2000) The effect of weather factors on fluctuations of grain prices in the Czech Lands in the 16th-18th centuries. Prace Geograficzne 108:19-25

Brázdil R, Dobrovolný P, Trnka M, Řezníčková L, Dolák L, Kotyza O (2019) Extreme droughts and human responses to them: the Czech Lands in the pre-instrumental period. Clim Past 15:1-24

Breitenmoser P, Beer J, Brönnimann S, Frank D, Steinhilber F, Wanner H (2012) Solar and volcanic fingerprints in tree-ring chronologies over the past 2000 years. Palaeogeogr Palaeoclimatol Palaeoecol 313:127-139

Briffa K, van der Schrier G, Jones P (2009) Wet and dry summers in Europe since 1750: evidence of increasing drought. Int J Climatol 29:1894-1905

Brückner E (1895) Der Einfluß der Klimaschwankungen auf die Ernteerträge und Getreidepreise in Europa. Geogr Z 1:39-51, 100-108

Brunt L (2015) Weather shocks and English wheat yields, 1690-1871. Explor Econ Hist 57:50-58

Büntgen U, Franke J, Frank D, Wilson R, González-Rouco F, Esper J (2010) Assessing the spatial signature of European climate reconstructions. Clim Res 41:125-130

Callahan J, Casey R, Sharer G, Templeton M (2019) IRISSeismic: classes and methods for seismic data analysis. https://CRAN.R-project.org/package=IRISSeismic

Camenisch C (2015) Endlose Kälte. Witterungsverlauf und Getreidepreise in den Burgundischen Niederlanden im 15. Jahrhundert. Schwabe, Basel

Camenisch C, Rohr C (2018) When the weather turned bad. The research of climate impacts on society and economy during the Little Ice Age in Europe: An overview. Cuadernos de investigación geográfica 44:99-114

Campbell BM (2010) Nature as historical protagonist: environment and society in pre-industrial England. Econ Hist Rev 63:281-314

Campbell BM (2016) The Great Transition: climate, disease and society in the late-medieval world. Cambridge University Press, Cambridge

Camuffo D, Della Valle A, Bertolin C, Santorelli E (2016) The Stancari air thermometer and the 17151737 record in Bologna, Italy. Clim Change 139:623-636

Camuffo D, Della Valle A, Bertolin C, Santorelli E (2017) Temperature observations in Bologna, Italy, from 1715 to 1815: a comparison with other contemporary series and an overview of three centuries of changing climate. Clim Change 142:7-22

Carrington RC (1863) Observations of the Spots on the Sun: from November 9, 1853, to March 24, 1861, made at Redhill. Williams and Norgate, London

Chakrabarty D (2009) The climate of history: Four theses. Crit Inq 35:197-222

Chambers F (1886) Sunspots and prices of Indian food-grains. Nature 34:100-104

Chilosi D, Murphy TE, Studer R, Tunçer AC (2013) Europe's many integrations: geography and grain markets, 1620-1913. Explor Econ Hist 50:46-68

Christiansen B (2007) Atmospheric circulation regimes: can cluster analysis provide the number? J Clim 20:2229-2250

Christiansen B (2013) Changes in temperature records and extremes: are they statistically significant? J Clim 26:7863-7875

Christiansen B, Ljungqvist FC (2017) Challenges and perspectives for large-scale temperature reconstructions of the past two millennia. Rev Geophys 55:40-96

Christiansen B, Schmith T, Thejll P (2009) A surrogate ensamble study of climate reconstruction methods: stochasticity and robustness. J Clim 22:951-976

Claridge J, Langdon J (2011) Storage in medieval England: the evidence from purveyance accounts, 1295-1349. Econ Hist Rev 64:1242-1265 
Collet D (2010) Storage and starvation: public granaries as agents of food security in early modern Europe. Hist Soc Res 35:234-252

Cook ER, Krusic PJ (2005) ARSTAN: a tree-ring standardization program based on detrending and autoregressive time series modeling with interactive graphics. http://www.ldeo.columbia.edu/treering-laboratory/resources/software

Cook ER, Peters K (1981) The smoothing spline: a new approach to standardizing forest interior tree-ring width series for dendroclimatic studies. Tree-ring Bull 4:45-53

Cook ER, Peters K (1997) Calculating unbiased tree-ring indices for the study of climatic and environmental change. Holocene 7:361-370

Cook ER, Seager R, Kushnir Y, Briffa KR, Büntgen U, Frank D, Krusic PJ, Tegel W, van der Schrier G, Andreu-Hayles L, Baillie M, Baittinger C, Bleicher N, Bonde N, Brown D, Carrer M, Cooper R, Čufar K, Dittmar C, Esper J, Griggs C, Gunnarson B, Günther B, Gutierrez E, Haneca K, Helama S, Herzig F, Heussner KU, Hofmann J, Janda P, Kontic R, Köse N, Kyncl T, Levanič T, Linderholm H, Manning S, Melvin TM, Miles D, Neuwirth B, Nicolussi K, Nola P, Panayotov M, Popa I, Rothe A, Seftigen K, Seim A, Svarva H, Svoboda M, Thun T, Timonen M, Touchan R, Trotsiuk V, Trouet V, Walder F, Ważny T, Wilson R, Zang C (2015) Old World megadroughts and pluvials during the Common Era. Sci Adv 1(e1500):561

De Kraker AM (2017) Ice and water: the removal of ice on waterways in the Low Countries, 1330-1800. Water Hist 9:109-128

De Vries J (1980) Measuring the impact of climate on history: the search for appropriate methodologies. J Interdiscip Hist 10:599-630

Dobrovolný P, Moberg A, Brázdil R, Pfister C, Glaser R, Wilson R, van Engelen A, Limanówka D, Kiss A, Halíčková M, Macková J, Riemann D, Luterbacher J, Böhm R (2010) Monthly, seasonal and annual temperature reconstructions for Central Europe derived from documentary evidence and instrumental records since AD 1500. Clim Change 101:69-107

Ebeling D, Irsigler F (1976) Getreideumsatz, Getreide- und Brotpreise in Köln, 1368-1797. Böhlau-Verlag, Cologne

Eddy JA (1976) The Maunder minimum. Science 192:1189-1202

Edvinsson R (2009) Swedish harvests, 1665-1820: Early modern growth in the periphery of European economy. Scand Econ Hist Rev 57:2-25

Edvinsson R (2012) Harvests and grain prices in Sweden, 1665-1870. Agric Hist Rev 60:1-18

Edvinsson R, Leijonhufvud L, Söderberg J (2009) Väder, skördar och priser i Sverige. In: Liljewall B, Flygare IA, Lange U, Ljunggren L, Söderberg J (eds) Agrarhistoria på många sätt: 28 studier om människan och jorden. Festskrift till Janken Myrdal på hans 60-årsdag, The Royal Swedish Academy of Agriculture and Forestry, Stockholm, pp 115-136

Elsas MJ (1936-1949) Umriss einer geschichte der preise und löhne in Deutschland: vom ausgehenden mittelalter bis zum beginn des neunzehnten jahrhunderts. AW Sijthoff, Leiden

Esper J, Büntgen U, Luterbacher J, Krusic PJ (2013) Testing the hypothesis of post-volcanic missing rings in temperature sensitive dendrochronological data. Dendrochronologia 31:216-222

Esper J, Schneider L, Krusic PJ, Luterbacher J, Büntgen U, Timonen M, Sirocko F, Zorita E (2013) European summer temperature response to annually dated volcanic eruptions over the past nine centuries. Bull Volcanol 75:736

Esper J, Büntgen U, Denzer S, Krusic PJ, Luterbacher J, Schäfer R, Schreg R, Werner J (2017) Environmental drivers of historical grain price variations in Europe. Clim Res 72:39-52

Faraglia NF (1878) Storia dei prezzi in Napoli dal 1131 al 1860. A. Forni, Naples

Federico G (2011) When did European markets integrate? Eur Rev Econ Hist 15:93-126

Feliu G (1991) Precios y salarios en la Cataluña moderna. Banco de España, Madrid

Fogel RW (1992) Second thoughts on the European escape from hunger: famines, price elasticities, entitlements, chronic malnutrition, and mortality rates. In: Osmani SR (ed) Nutrition and poverty. Clarendon Press, Oxford, pp 243-286

Frêche G, Frêche G (1967) Les prix des grains des vins et des legumes a Toulouse, 1486-1868. Presses universitaires de France, Paris

Garnett R, Nirupama N, Haque CE, Murty T (2006) Correlates of Canadian Prairie summer rainfall: implications for crop yields. Clim Res 32:25-33

Glaser R, Riemann D (2009) A thousand-year record of temperature variations for Germany and Central Europe based on documentary data. J Quat Sci 24:437-449 
Gray LJ, Beer J, Geller M, Haigh JD, Lockwood M, Matthes K, Cubasch U, Fleitmann D, Harrison G, Hood L, J L, GA M, D S, van Geel B, W W (2010) Solar influences on climate. Rev Geophys 48:RG4001

Haigh J (1996) The impact of solar variability on climate. Science 272:981-984

Haigh JD (2003) The effects of solar variability on the Earth's climate. Philos Trans R Soc Lond A 361:95-111

Hamilton EJ (1934) American treasure and the price revolution in Spain, 1501-1650. Harvard University Press, Cambridge, MA

Hamilton EJ (1936) Money, prices, and wages in Valencia, Aragon, and Navarre, 1351-1500. Harvard University Press, Cambridge, MA

Hamilton EJ (1947) War and prices in Spain: 1651-1800. Harvard University Press, Cambridge, MA

Hanauer A (1878) Études économiques sur l'Alsace ancienne et moderne. A. Durand \& Pédone-Lauriel, Paris

Hansen TI (2015) Med kongen som redningsmann - Kornmagasin som klimatilpasning på 1700-tallet. Heimen 52:233-248

Harrison VL (1976) Do sunspot cycles affect crop yields? US Department of Agriculture, Economic Research Service

Hauser H (1936) Recherches et documents sur l'histoire des prix en France depuis 1500 à 1800. Les Presses modernes, Paris

Herman JR, Goldberg RA (1978) Sun, weather and climate. NASA SP-426, Washington, D.C

Herschel W (1801) Observations tending to investigate the nature of the Sun, in order to find the causes or symptoms of its variable emission of light and heat; with remarks on the use that may possibly be drawn from solar observations. Philos Trans Royal Soc 91:265-318

Hoffman PT (1996) Growth in a traditional society: the French countryside, 1450-1815. Princeton University Press, Princeton

Hoskins WG (1964) Harvest fluctuations and English economic history, 1480-1619. Agric Hist Rev $12: 28-46$

Hoskins WG (1968) Harvest fluctuations and English economic history, 1620-1759. Agric Hist Rev $16: 15-31$

Hoyt DV, Schatten K (1997) The role of the sun in climate change. Oxford University Press, Oxford

Huhtamaa H (2018) Combining written and tree-ring evidence to trace past food crises: a case study from Finland. In: Collet D, Schuh M (eds) Famines during the 'Little Ice Age' (1300-1800). Springer, Berlin/Heidelberg, pp 43-66

Huhtamaa H, Helama S (2017) Distant impact: tropical volcanic eruptions and climate-driven agricultural crises in seventeenth-century Ostrobothnia, Finland. J Hist Geogr 57:40-51

Huhtamaa H, Helama S (2017) Reconstructing crop yield variability in Finland: long-term perspective of the cultivation history on the agricultural periphery since AD 760. Holocene 27:3-11

Jacks DS (2004) Market integration in the North and Baltic Seas, 1500-1800. J Eur Econ Hist 33:285-329

Jevons WS (1878) Commercial crises and sun-spots. Nature 19:33-37

Jevons WS (1879) Sun-spots and commercial crises. Nature 19:588-590

Jones PD (2001) Early European instrumental records. In: Jones PD, Ogilvie AEJ, Davies T, Briffa K (eds) History and climate: memories of the future? Springer, Berlin/Heidelberg, pp 55-77

Jungclaus J, Bard E, Baroni M, Braconnot P, Cao J, Chini L, Egorova T, Evans M, González-Rouco JF, Goosse H, Hurtt GC, Joos F, Kaplan JO, Khodri M, Klein Goldewijk K, Krivova N, LeGrande AN, Lorenz SJ, Luterbacher J, Man W, Maycock AC, Meinshausen M, Moberg A, Muscheler R, Nehrbass-Ahles C, Otto-Bliesner BI, Phipps SJ, Pongratz J, Rozanov E, Schmidt GA, Schmidt H, Schmutz W, Schurer A, Shapiro AI, Sigl M, Smerdon JE, Solanki SK, Timmreck C, Toohey M, Usoskin IG, Wagner S, Wu CJ, Yeo KL, Zanchettin D, Zhang Q, Zorita E (2017) The PMIP4 contribution to CMIP6-Part 3: the last millennium, scientific objective, and experimental design for the PMIP4 past1000 simulations. Geosci Model Dev 10:4005-4033

Kain R (1979) Tithe as an index of pre-industrial agricultural production. Agric Hist Rev 27:73-81

Kelly M, Ó Gráda C (2014a) Change points and temporal dependence in reconstructions of annual temperature: did Europe experience a Little Ice Age? Ann Appl Stat 8:1372-1394

Kelly M, Ó Gráda C (2014b) "The waning of the Little Ice Age": climate change in early modern Europe. $\mathrm{J}$ Interdiscip Hist 44:301-325

King J, Hurst E, Slater A, Smith P, Tamkin B (1974) Agriculture and sunspots. Nature 252:2-3 
Krämer D (2015) "Menschen grasten nun mit dem Vieh": Die letzte grosse Hungerkrise der Schweiz 1816/17. Mit einer theoretischen und methodischen Einführung in die historische Hungerforschung, Schwabe, Basel

Landsteiner E (1999) The crisis of wine production in late sixteenth-century central Europe: climatic causes and economic consequences. Clim Change 43:323-334

Landsteiner E (2005) Wenig Brot und saurer Wein. Kontinuität und Wandel in der zentraleuropäischen Ernährungskultur im letzten Drittel des 16. Jahrhunderts. In: Behringer W, Lehmann H, Pfister C (eds) Kulturelle Konsequenzen der "Kleinen Eiszeit", Vandenhoeck \& Ruprecht, Göttingen, pp 87-147

Laurenz L, Lüdecke HJ, Lüning S (2019) Influence of solar activity changes on European rainfall. J Atmos Sol-Terr Phys 185:29-42

Le Roy Ladurie E (1967) Histoire du climat depuis l'an mil. Flammarion, Paris

Le Roy Ladurie E, Goy J (1982) Tithe and Agrarian history from the fourteenth to the nineteenth century: an essay in comparative history. Cambridge University Press, Cambridge

Leijonhufvud L (2001) Grain tithes and manorial yields in early modern sweden: trends and patterns of production and productivity c. 1540-1680. Swedish University of Agricultural Sciences, Ulltuna

Leino MW (2017) Spannmål: svenska lantsorter. Nordiska museets förlag, Stockholm

Lilensten J, de Wit TD, Matthes K (eds) (2015) Earth's climate response to a changing sun. EDP Sciences, Les Ulis

Ljungqvist FC (2017) Human and societal dimensions of past climate change. In: Crumley CL, Westin A, Lennartsson T (eds) Issues and concepts in historical ecology: the past and future of landscapes and regions. Cambridge University Press, Cambridge, pp 41-83

Ljungqvist FC, Krusic PJ, Sundqvist HS, Zorita E, Brattström G, Frank D (2016) Northern Hemisphere hydroclimate variability over the past twelve centuries. Nature 532:94-98

Ljungqvist FC, Tegel W, Krusic PJ, Seim A, Gschwind FM, Haneca K, Herzig F, Heussner KU, Hofmann J, Houbrechts D, Kontic R, Kyncl T, Leuschner H, Nicolussi K, Perrault C, Pfeifer K, Schmidhalter M, Seifert M, Walder F, Westphal T, Büntgen U (2018) Linking European building activity with plague history. J Archaeol Sci 98:81-92

Ljungqvist FC, Seim A, Krusic PJ, González-Rouco JF, Werner JP, Cook ER, Zorita E, Luterbacher J, Xoplaki E, Destouni G, García-Bustamante E, Aguilar CAM, Seftigen K, Wang J, Gagen MH, Esper J, Solomina O, Fleitmann D, Büntgen U (2019) European warm-season temperature and hydroclimate since 850 CE. Environ Res Lett 14:084015

Ljungqvist FC, Seim A, Huhtamaa H (2021) Climate and society in European history. Wiley Interdiscip Rev Clim Change 12:e691

Lombardini G (1963) Pane e denaro a Bassano. Neri Pozza, Venice

Love JJ (2013) On the insignificance of Herschel's sunspot correlation. Geophys Res Lett 40:4171-4176

Luterbacher J, Werner JP, Smerdon JE, Fernández-Donado L, González-Rouco F, Barriopedro D, Ljungqvist FC, Büntgen U, Zorita E, Wagner S, Esper J, Frank D, Barriendos M, Bertolin C, Bothe O, Brázdil R, Camuffo D, Dobrovolný P, Gagen M, García-Bustamante E, Ge Q, Gómez-Navarro J, Guiot J, Hao Z, Hegerl G, Holmgren K, Jungclaus J, Klimenko V, Martín-Chivelet J, McCarroll D, Pfister C, Roberts N, Schindler A, Schurer A, Solomina O, Toreti A, von Gunten L, Wahl E, Wanner H, Wetter O, Xoplaki E, Yuan N, Zanchettin D, Zhang H, Zerefos C (2016) European summer temperatures since Roman times. Environ Res Lett 11:024001

Malanima P (1976) Aspetti di mercato e prezzi del grano e della segale a Pisa dal 1548 al 1818. In: Ricerche di storia moderna. Pacini, Pisa, pp 288-327

Manley G (1974) Central England temperatures: monthly means 1659 to 1973. Q J R Meteorol Soc 100:389-405

Mauelshagen F (2010) Klimageschichte der Neuzeit. Wissenschaftliche Buchgesellschaft, Darmstadt

McCloskey DN, Nash J (1984) Corn at interest: the extent and cost of grain storage in medieval England. Am Econ Rev 74:174-187

Michaelowa A (2001) The impact of short-term climate change on British and French agriculture and population in the first half of the 18th century. In: Jones PD, Ogilvie AEJ, Davies T, Briffa K (eds) History and climate: memories of the future? Springer, Berlin/Heidelberg, pp 201-217

Mitchell BR (1971) Abstract of British historical statistics. Cambridge University Press, Cambridge

Moberg A, Bergström H (1997) Homogenization of Swedish temperature data. Part III: The long temperature records from Uppsala and Stockholm. Int J Climatol 17:667-699

Mrgić J (2011) Wine or raki - the interplay of climate and society in early modern Ottoman Bosnia. Environ Hist 17:613-637 
Muñoz-Jaramillo A, Vaquero JM (2019) Visualization of the challenges and limitations of the long-term sunspot number record. Nat Astron 3:205-211

Murtagh F, Legendre P (2014) Ward's hierarchical agglomerative clustering method: which algorithms implement Ward's criterion? J Classif 31:274-295

Nielsen R (1997) Storage and English government intervention in early modern grain markets. J Econ Hist $57: 1-33$

Oberschelp R (1986) Beiträge zur niedersächsischen Preisgeschichte des 16. bis 19. Jahrhunderts. Verlag August Lax Hildesheim, Hannover

Parenti G (1942) Prezzi e mercato del grano a Siena (1546-1765). Casa, Cya, Florence

Pei Q, Zhang D, Lee H, Li G (2016) Crop management as an agricultural adaptation to climate change in early modern era: a comparative study of eastern and western Europe. Agriculture 6:29

Pelc J (1937) Ceny w Gdańsku w XVI i XVII wieku. skł. gł. Kasa im. Mianowskiego-Instytut Popierania Polskiej Twórczości Naukowej, Lwów

Peristykh AN, Damon PE (2003) Persistence of the Gleissberg 88-year solar cycle over the last $\sim 12,000$ years: evidence from cosmogenic isotopes. J Geophys Res Space Phys 108:1003

Persson KG (1999) Grain markets in Europe, 1500-1900: integration and deregulation. Cambridge University Press, Cambridge

Pfister C (1988) Fluctuations climatiques et prix céréaliers en Europe du $\mathrm{XVI}^{e}$ au $\mathrm{XX}^{e}$ siècle. Ann Hist Sci Soc 43:25-53

Pfister C (2005) Weeping in the snow: The second period of Little Ice Age-type impacts, 1570-1630. In: Behringer W, Lehmann H, Pfister C (eds) Kulturelle Konsequenzen der "Kleinen Eiszeit", Vandenhoeck \& Ruprecht, Göttingen, pp 31-86

Pfister C, Brázdil R (1999) Climatic variability in sixteenth-century Europe and its social dimension: a synthesis. Clim Change 43:5-53

Poluianov SV, Kovaltsov GA, Mishev AL, Usoskin IG (2016) Production of cosmogenic isotopes ${ }^{7} \mathrm{Be},{ }^{10}$ $\mathrm{Be},{ }^{14} \mathrm{C},{ }^{22} \mathrm{Na}$, and ${ }^{36} \mathrm{Cl}$ in the atmosphere: altitudinal profiles of yield functions. J Geophys Res Atmos 121:8125-8136

Posthumus NW (1946-1964) Inquiry into the history of prices in Holland. Brill, Leiden, E.J

Poynting JH (1884) A comparison of the fluctuations in the price of wheat and in the cotton and silk imports into Great Britain. J Stat Soc Lond 47:34-74

Pribram AF (1938) Materialien zur Geschichte der Preise und Löhne in Österreich. Carl Ueberreuters Verlag, Vienna

Pribyl K (2017) Farming, famine and plague: the impact of climate in Late Medieval England. Springer, Berlin/Heidelberg

Prichard D, Theiler J (1994) Generating surrogate data for time series with several simultaneously measured variables. Phys Rev Lett 73:951-954

Pustil'nik LA, Din GY (2004) Influence of solar activity on the state of the wheat market in medieval England. Sol Phys 223:335-356

Pustil'nik LA, Din GY (2009) Possible space weather influence on the Earth wheat markets. Sun Geosph $4: 35-43$

R Core Team (2020) R: a language and environment for statistical computing. R Foundation for Statistical Computing, Vienna, Austria

Rahlf T (1996) Getreide in der Sozial- und Wirtschaftsgeschichte vom 16. bis 18. Jahrhundert, Das Beispiel Köln im regionalen Vergleich. Auenthal Verlag, Trier

Rogers JT (1887) Agriculture and prices in England, vol I-VIII. Clarendon Press, Oxford

Santiago-Caballero C (2014) Tithe series and grain production in central Spain, 1700-1800. Rural Hist 25:15-37

Schneider EB (2014) Prices and production: agricultural supply response in fourteenth-century England. Econ Hist Rev 67:66-91

Schreiber T, Schmitz A (2000) Surrogate time series. Physica D 142:346-382

Scott S, Duncan SR, Duncan CJ (1998) The origins, interactions and causes of the cycles in grain prices in England, 1450-1812. Agric Hist Rev 46:1-14

SILSO World Data Center (1994-2014) Sunspot number and long-term solar observations, Royal Observatory of Belgium. http://www.sidc.be/silso/

Siscoe GL (1978) Solar-terrestrial influences on weather and climate. Nature 276:348-352

Slicher van Bath BH (1963) Yield ratios, 1810-1820. Universiteit Wageningen, Wageningen, Afdeling Agrarische Geschiedenis 
Söderberg J (2006) Grain prices in Cairo and Europe in the Middle Ages. Research in economic history. Bingley, Emerald, pp 189-216

Steinhilber F, Beer J, Fröhlich C (2009) Total solar irradiance during the Holocene. Geophys Res Lett 36(L19):704

Stephenson F (1990) Historical evidence concerning the sun: interpretation of sunspot records during the telescopic and pretelescopic eras. Philos Trans R Soc A 330:499-512

Studer R (2015) The great divergence reconsidered. Cambridge University Press, Cambridge

Svalgaard L, Schatten KH (2016) Reconstruction of the sunspot group number: the backbone method. Sol Phys 291:2653-2684

Svensmark H, Bondo T, Svensmark J (2009) Cosmic ray decreases affect atmospheric aerosols and clouds. Geophys Res Lett 36:L15101

Taricco C, Mancuso S, Ljungqvist F, Alessio S, Ghil M (2015) Multispectral analysis of Northern Hemisphere temperature records over the last five millennia. Clim Dynam 45:83-104

Tello E, Martínez JL, Jover-Avellà G, Olarieta JR, García-Ruiz R, de Molina MG, Badia-Miró M, Winiwarter V, Koepke N (2017) The onset of the English agricultural revolution: climate factors and soil nutrients. J Interdiscip Hist 47:445-474

Thejll PA (2001) Decadal power in land air temperatures: is it statistically significant? J Geophys Res Atmos 106:31693-31702

Unger RW (2011) Shipping and economic growth 1350-1850. Brill, Leiden

Van Tielhof M (2002) The 'Mother of all Trades': the Baltic grain trade in Amsterdam from the late 16th to the early 19 th century. Brill, Leiden

Van Zanden JL (1999) Wages and the standard of living in Europe, 1500-1800. Eur Rev Econ Hist 3:175-197

Verlinden C (1959) Dokumenten voor de geschiedenis van prijzen en lonen in Vlaanderen en Brabant. De Tempel, Bruges

Wang J, Yang B, Ljungqvist FC, Luterbacher J, Osborn TJ, Briffa KR, Zorita E (2017) Internal and external forcing of multidecadal Atlantic climate variability over the past 1,200 years. Nat Geosci 10:512-517

Ward JH (1963) Hierarchical grouping to optimize an objective function. J Am Stat Assoc 58:236-244

White S, Brooke J, Pfister C (2018) Climate, weather, agriculture, and food. In: White S, Pfister C, Mauelshagen F (eds) The Palgrave handbook of climate history. Springer, Berlin/Heidelberg, pp 331-353

Wrigley E (1989) Some reflections on corn yields and prices in pre-industrial economies. In: Walter J, Schofield R (eds) Famine, disease and the social order in early modern society. Cambridge University Press, Cambridge, pp 235-278

Publisher's Note Springer Nature remains neutral with regard to jurisdictional claims in published maps and institutional affiliations.

\section{Authors and Affiliations}

\section{Fredrik Charpentier Ljungqvist ${ }^{1,2,3}$ (1) $\cdot$ Peter Thejll ${ }^{4}$. Bo Christiansen ${ }^{4}$. Andrea Seim $^{5,6}$. Claudia Hartt ${ }^{7}$. Jan Esper ${ }^{7}$}

1 Department of History, Stockholm University, 10691 Stockholm, Sweden

2 Bolin Centre for Climate Research, Stockholm University, 10691 Stockholm, Sweden

3 Swedish Collegium for Advanced Study, Linneanum, Thunbergsvägen 2, 75238 Uppsala, Sweden

4 Danish Meteorological Institute, Lyngbyvej 100, 2100 Copenhagen $\varnothing$, Denmark

5 Chair of Forest Growth and Dendroecology, Institute of Forest Sciences, Albert Ludwig University of Freiburg, 79106 Freiburg, Germany

6 Department of Botany, University of Innsbruck, 6020 Innsbruck, Austria

7 Department of Geography, Johannes Gutenberg University, 55128 Mainz, Germany 